\title{
The Genus Fejervarya (Anura: Ranidae) in Central Western Ghats, India, with Descriptions of Four New Cryptic Species
}

Author(s): Mitsuru Kuramoto, S. Hareesh Joshy, Atsushi Kurabayashi, and Masayuki Sumida

Source: Current Herpetology, 26(2):81-105.

Published By: The Herpetological Society of Japan

DOI: http://dx.doi.org/10.3105/1881-1019(2007)26[81:TGFARI]2.0.CO;2

URL: http://www.bioone.org/doi/

full/10.3105/1881-1019\%282007\%2926\%5B81\%3ATGFARI\%5D2.0.CO\%3B2

BioOne (www.bioone.org) is a nonprofit, online aggregation of core research in the biological, ecological, and environmental sciences. BioOne provides a sustainable online platform for over 170 journals and books published by nonprofit societies, associations, museums, institutions, and presses.

Your use of this PDF, the BioOne Web site, and all posted and associated content indicates your acceptance of BioOne's Terms of Use, available at www.bioone.org/page/terms_of_use.

Usage of BioOne content is strictly limited to personal, educational, and non-commercial use. Commercial inquiries or rights and permissions requests should be directed to the individual publisher as copyright holder. 


\title{
The Genus Fejervarya (Anura: Ranidae) in Central Western Ghats, India, with Descriptions of Four New Cryptic Species
}

\author{
MITSURU KURAMOTO ${ }^{1}$ *, S. HAREESH JOSHY ${ }^{2}$, \\ ATSUSHI KURABAYASHI ${ }^{3}$, AND MASAYUKI SUMIDA ${ }^{3}$ \\ 1 3-6-15 Hikarigaoka, Munakata, Fukuoka 811-3403, JAPAN \\ ${ }^{2}$ Rondano Biodiversity Research Laboratory, St. Aloysius College, Mangalore 575003 , \\ Karnataka, INDIA \\ ${ }^{3}$ Institute for Amphibian Biology, Graduate School of Science, Hiroshima University, \\ Higashihiroshima, Hiroshima 739-8526, JAPAN
}

\begin{abstract}
We compared six taxa of the genus Fejervarya from central Western Ghats, southwestern India, including $F$. rufescens, $F$. sahyadris, and four taxa that possess distinct mtDNA haplotypes as demonstrated by our previous studies. Morphological comparisons with $F$. brevipalmata, $F$. keralensis, $F$. nilagirica, and $F$. syhadrensis on the basis of literature descriptions and museum specimens revealed that the four haplotypes do not correspond to any of the previously described species. Therefore, they are named herein as new species. Although each of these new species was separated clearly by discriminant analyses, two large-bodied species, as well as two small-bodied species, occurring sympatrically or parapatrically in many collecting sites, were very similar to each other in external appearance. Acoustic characteristics available for five of the six species were most conspicuous and diagnostic features. This study revealed the occurrence of active speciation in Fejervarya in the Western Ghats, one of the hot spots of biodiversity in the world.
\end{abstract}

Key words: Fejervarya; New species; Morphology; Advertisement call; Western Ghats; India

\section{INTRODUCTION}

The genus Fejervarya of the family Ranidae contains 32 species distributed widely over southern and southeastern Asia, from India, Sri Lanka and Nepal eastwards to Indonesia, China and Japan (Frost, 2007). More than half of the species occur in India and Sri Lanka, and 11 species are known from the Western Ghats, southwestern India. Members

* Corresponding author. Tel/Fax: +81-940-320730; E-mail address: kuramoto@hyu.bbiq.jp of this genus are medium to small in size and have a dark brown, more or less wrinkled dorsum. They live around shallow standing waters, such as paddy fields, wetlands, ditches, and temporary pools, where they lay eggs.

Biochemical and molecular phylogenetic analyses (Toda et al., 1998; Kurabayashi et al., 2005; Djong et al., 2007) indicated the existence of several cryptic species in Fejervarya from several localities in its wide distribution range, and Dubois and Ohler (2000) and Veith et al. (2001) partially revised the taxonomy of the Fejervarya species from southeastern Asia. 
However, the status of southern Asian species are still in confusion, except for those of Nepal (Anders, 2002) and Sri Lanka (Dutta and Manamendra-Arachchi, 1996).

During an amphibian survey in southwestern Karnataka, India, we noticed the presence of large- and small-bodied Fejervarya frogs in samples from various localities in the central Western Ghats, besides $F$. rufescens and $F$. sahyadris. To examine whether these forms are distinct taxa or merely represent intraspecific variants, we analyzed mtDNA sequences of these samples. As a result, four distinct mtDNA haplotypes were recognized, two for the large-bodied form and the remaining two for the small-bodied form, besides those of $F$. rufescens and $F$. sahyadris (Kurabayashi et al., 2005; Sumida et al., unpublished data). Morphological features of these large-bodied and small-bodied forms did not fit those given in the published descriptions of Indian species of Fejervarya.

We therefore analyze morphological characters for the four genetically distinct entities in detail, and describe each of them as a new species below. We further provide preliminary acoustic data for some of these and other species of Fejervarya.

\section{MATERIALS AND METHODS}

Observations and samplings were made from 2000 to 2006 in the following areas: Padil, Kadri, and Bajipe of Mangalore; Bhatkal, Udupi and Karnoor of Dakshin Kannad District, Talagini of Shimoga District, Kudremukh and Mudigere of Chikmagalur District, Talapu and Made of Madikeri, and Kirundadu of Kodagu District, all in Karnataka; and Aralam of Kannur District, Kerala (Fig. 1).

The results of phylogenetic analyses of mtDNA sequence data for the southwest Indian Fejervarya, obtained in our previous study (Kurabayashi et al., 2005), are summarized in Fig. 2. The four putative undescribed species, each exhibiting a unique haplotype, are referred to as hpL1, hpL2, hpS1 and hpS2, with $\mathrm{L}$ and $\mathrm{S}$ indicating large- and small-bodied forms, respectively. The numbers of individuals subjected to mtDNA sequencing were six for hpL1, six for hpL2, 10 for hpS1, and 17 for hpS2. We first compared these specimens in preserved state and clarified their discriminant

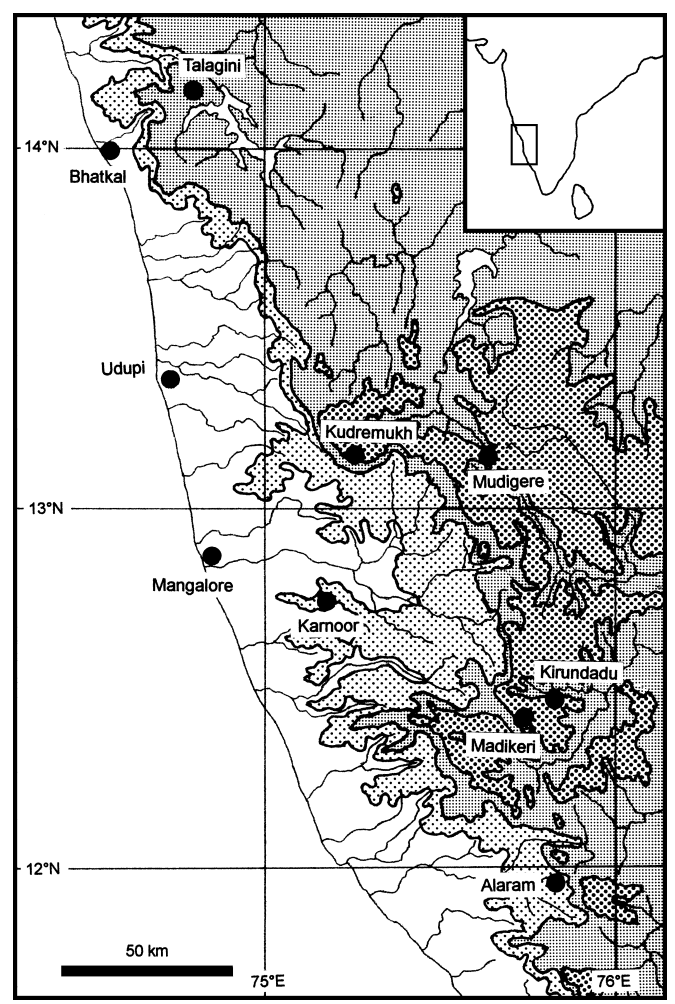

FIG. 1. Collecting sites of specimens of Fejervarya in southwestern India. Contours indicate 100, 450 and $900 \mathrm{~m}$ asl.

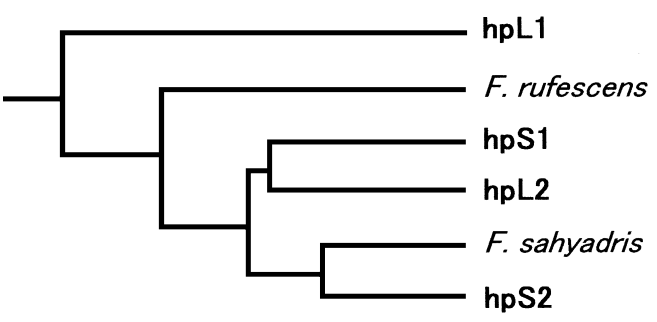

FIG. 2. Phylogenetic relationships among six species and haplotypes of Fejervarya from central Western Ghats, India (redrawn from Kurabayashi et al. [2005] with modifications on the basis of additional unpublished data). See text for abbreviations of mtDNA haplotypes (hpL1, hpL2, hpS1 and hpS2). 
characters. We then assigned other specimens, for which mtDNA sequence data were not available, to one of the four species accordingly. Type specimens were deposited in the Natural History Collections of the Bombay Natural History Society (BNHS). All other specimens were deposited in the Rondano Biodiversity Research Laboratory (RBRL), St. Aloysius College, Mangalore.

Following measurements were taken to nearest $0.1 \mathrm{~mm}$ using digital calipers: snout-vent length (SVL), from tip of snout to vent; head length (HL), from tip of snout to jaw angle; head width (HW), distance between jaw angles; snout to nostril distance (S-N), from tip of snout to nostril; inter-nostril distance (N-N), distance between nostrils; nostril to eye distance (N-E), from nostril to anterior corner of eye; eye diameter (ED), horizontal diameter of eye; inter-orbital distance (E-E), distance between inner borders of upper eyelids; eyelid width (ELW), at broadest part of eyelid; tympanum diameter (TD), horizontal diameter of tympanum; forearm and hand length (FHL), from elbow to tip of longest finger; forearm width (FAW), at the middle of forearm; hand length (HAL), from proximal base of thenal tubercle to tip of longest finger; no. 1 to no. 4 finger lengths (F1-F4), from junction between no. $n$ and no. (n-1) finger to tip of no. $\mathrm{n}$ finger, except F1 which was measured from junction between no. 1 and no. 2 finger; hindlimb length (HLL), from vent to tip of longest toe; femur (thigh) length (FEL), from vent to knee; tibia (shank) length (TIL), from knee to ankle; tarsus and foot length (TFL), from ankle to tip of longest toe; foot length (FOL), from proximal base of inner metatarsal tubercle to tip of longest toe; no. 1 to no. 5 toe lengths (T1-T5), measured by the same way as for finger lengths; inner metatarsal tubercle length (IMT), longitudinal length of inner metatarsal tubercle; outer metatarsal tubercle length (OMT), longitudinal length of outer metatarsal tubercle. The web formula follows Myers and Duellman (1982).

For comparisons, we measured preserved specimens of $F$. brevipalmata from Maha- rashtra and F. keralensis from Kerala deposited in the Natural History Collections of the Bombay Natural History Society (BNHS), and of $F$. nilagirica from Tamil Nadu, F. rufescens from Kempholey of Karnataka, and F. syhadrensis from western Nepal deposited in the Muséum national d'Histoire naturelle (MNHN). The measurements recorded for these specimens were SVL, HL, HW, S-N, N-N, N-E, ED, E-E, ELW, TD, HAL, F1, F2, FEL, TIL, FOL and IMT. Canonical discriminant analyses were performed using data for the above 17 measurements from our specimens, and the BNHS and MNHN specimens without prior transformation. For hpL1, only females were compared with other taxa, because mature males were not available. We used SPSS (15.0J) statistics software (SPSS Japan Inc.).

Advertisement calls were recorded in the field using a cassette recorder (Sony TCMAP5) or an MD recorder (Sony MZ-B10). The calls were analyzed by Avisoft-SASLab Light software (Avisoft Bioacoustics).

\section{MORPHOLOGICAL COMPARISONS}

The results of statistical analysis of the measurements are shown in Table 1. MannWhitney U-tests revealed that there were no significant differences in SVL between females of hpL1 and hpL2 $(\mathrm{U}=23 ; \mathrm{P}=0.315)$, between females of hpS1 and hpS2 $(\mathrm{U}=54 ; \mathrm{P}=0.243)$, and between males of hpS1 and hpS2 $(\mathrm{U}=173.5 ; \mathrm{P}=0.670)$. There were significant differences in SVL between females and males at the $5 \%(\mathrm{hpS} 1)$ or $1 \%$ level (hpL2 and hpS2).

Although SVLs did not differ significantly, females of hpL1 and hpL2 were separated clearly in a canonical discriminant analysis (Fig. 3A). Statistics for the discriminant analyses are shown in Table 2. Female specimens of the two small-bodied haplotypes, hpS1 and hpS2, were also completely separated from each other by the analysis (Fig. 3B, Table 2). In the discriminant analysis using male specimens of hpS1 and hpS2 (Table 2), three of the 14 specimens of hpS1 were classified as hpS2. 


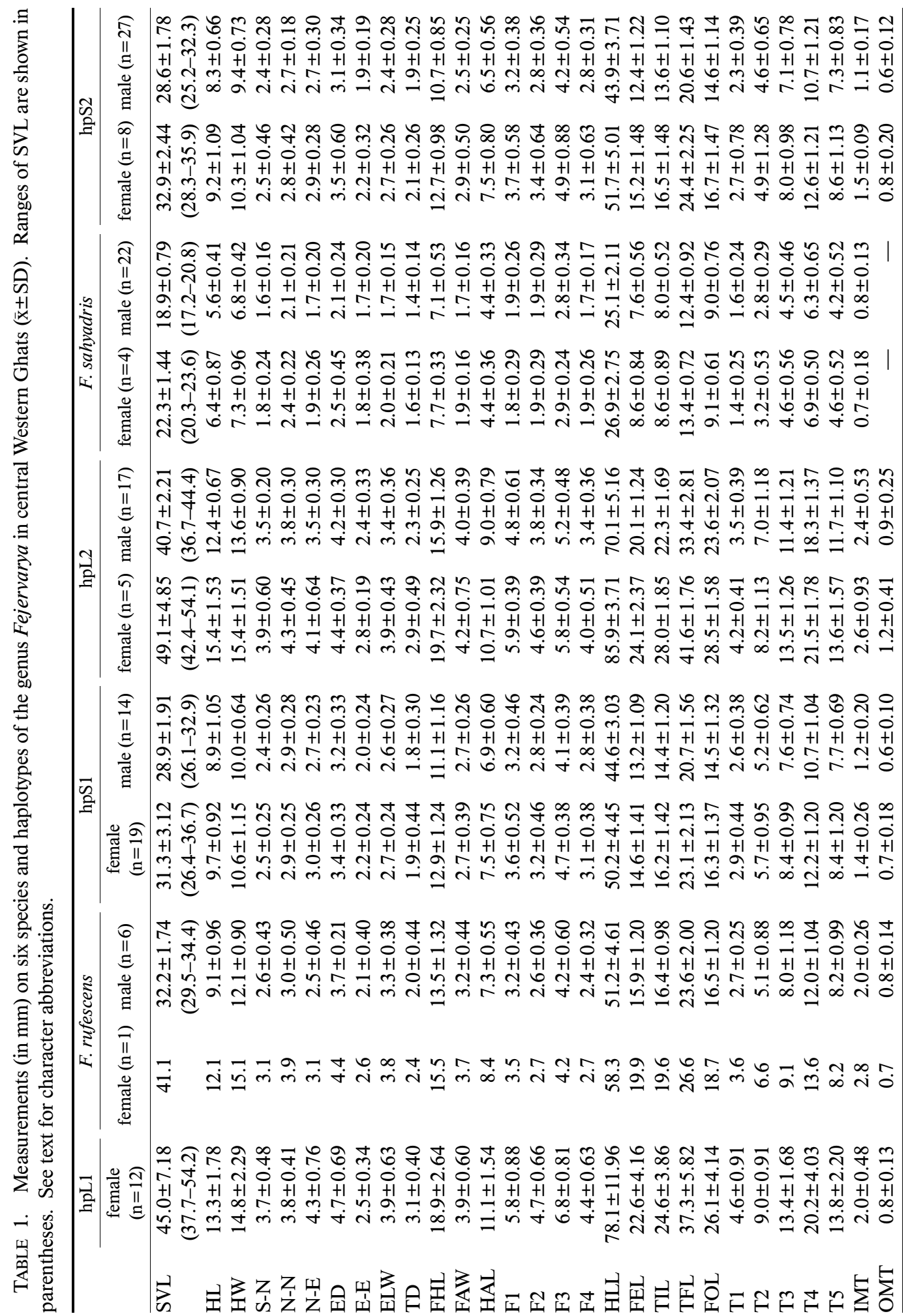



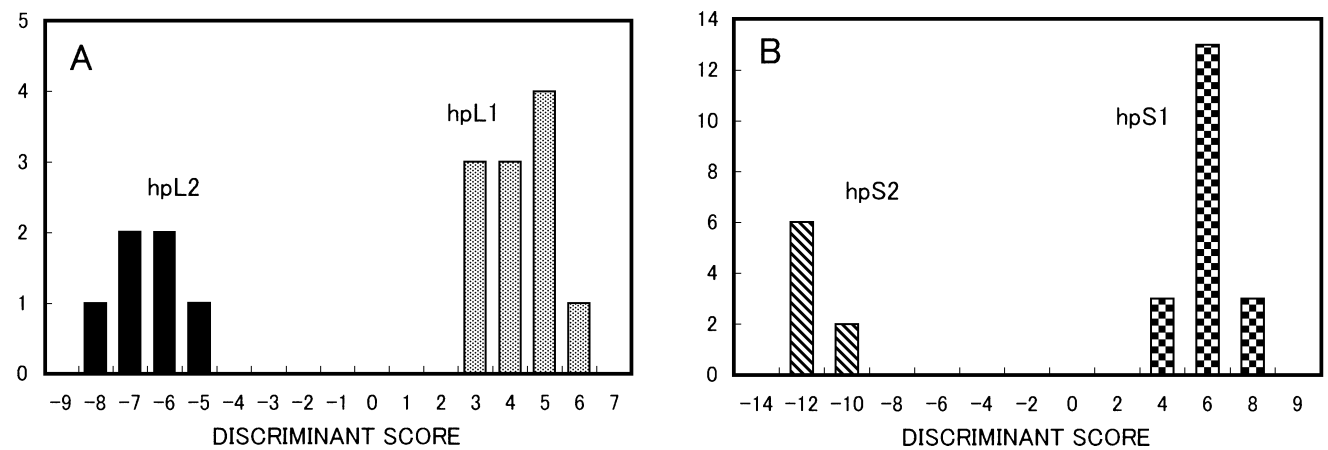

FIG. 3. Discriminant score frequencies for females of hpL1 and hpL2 (A) and females of hpS1 and hpS2 (B).

TABLE 2. Statistics obtained from discriminant analyses using six species and haplotypes of the genus Fejervarya. Abbreviations brev, keral, nilag, and syhad refer to F. brevipalamata, F. keralensis, F. nilagirica and $F$. syhadrensis, respectively.

\begin{tabular}{lccccccc}
\hline \multirow{2}{*}{ Taxa compared } & \multirow{2}{*}{ Sex } & \multicolumn{2}{c}{ Eigenvalue } & \multicolumn{2}{c}{ Wilks' lambda (P) } & \multicolumn{2}{c}{$\begin{array}{c}\text { Discriminant } \\
\text { result (\%) }\end{array}$} \\
\cline { 3 - 7 } Figure \\
\cline { 3 - 7 } hpL1, hpL2 & female & 13.634 & - & $0.068(0.044)$ & - & 100 & 3A \\
hpS1, hpS2 & female & 67.869 & - & $0.015(0.001)$ & - & 100 & 3B \\
hpS1, hpS2 & male & 4.541 & - & $0.180(0.008)$ & - & 97.6 & \\
hpS1, hpS2 & female, male & 3.363 & - & $0.229(<0.001)$ & - & 95.6 & \\
hpL1, brev, keral & female & 73.475 & 7.043 & $0.002(0.001)$ & $0.124(0.189)$ & 100 & $4 \mathrm{~A}$ \\
hpL2, brev, keral & female & 57.205 & 7.956 & $0.002(0.018)$ & $0.112(0.219)$ & 100 & $4 \mathrm{~B}$ \\
hpL2, brev, keral & male & 56.979 & 4.668 & $0.003(<0.001)$ & $0.196(0.091)$ & 100 & \\
hpL1, hpL2, nilag & female & 14.954 & 4.269 & $0.012(0.049)$ & $0.190(0.308)$ & 100 & 5A \\
hpL2, nilag & male & 17.552 & - & $0.054(0.009)$ & - & 100 & 5B \\
hpS1, hpS2, syhad & female & 5.251 & 1.334 & $0.069(<0.001)$ & $0.429(0.142)$ & 100 & 6A \\
hpS1, hpS2, syhad & male & 2.429 & 1.064 & $0.141(<0.001)$ & $0.484(0.002)$ & 87.3 & 6B \\
\hline
\end{tabular}

A total of 11 species of Fejervarya are known to occur in the Western Ghats (Frost, 2007). Many authors listed $F$. limnocharis (Gravenhorst, 1829) as a member of the Indian amphibian fauna (Boulenger, 1890; Chanda, 2002; Daniel, 2002; Daniels, 2005). However, molecular phylogenetic studies indicated that F. limnocharis is restricted to Indonesia, Malaysia, Laos, and Vietnam (Toda et al., 1998; Biju, 2001: Veith et al., 2001; Djong et al., 2007). Fei et al. (2002) resurrected $F$. multistriata (Hallowell, 1861) from a synonym of $F$. limnocharis and applied the name to Chinese "limnocharis", whereas the taxonomic status of the Japanese "limnocharis" remains to be determined in future studies. All Fejer- varya specimens from India and Bangladesh so far studied belong to a cluster that is distinct from the one consisting of $F$. limnocharis sensu stricto (see Djong et al. [2007]). Thus, it is concluded that the range of $F$. limnocharis is confined to southeastern Asia and that " $F$. limnocharis" from India is an assemblage of several cryptic taxa.

Except for $F$. rufescens (Jerdon, 1854) and F. sahyadris (Dubois, Ohler, and Biju, 2001), which are readily distinguishable from other Indian taxa, three large-sized (more than $40 \mathrm{~mm}$ in SVL) and five small-sized (30$40 \mathrm{~mm}$ in SVL) Fejervarya species have been described from the Western Ghats. The three large species are $F$. brevipalmata (Peters, 
1871), F. keralensis (Dubois, 1981) and $F$. nilagirica (Jerdon, 1854). Boulenger (1904) doubted the validity of the type locality of $F$. brevipalmata (Pegu, Burma=Myanmar) simply because he had seen numerous specimens of this species from southern India, and Dubois (1984) placed this taxon in incertae sedis. These species are similar to each other in external morphology and, except for a few combinations, such as $F$. keralensis and $F$. brevipalmata, lack features that clearly discriminate them from each other. We compared museum specimens of the three species with hpL1 and hpL2.

The two large-bodied haplotypes, hpL1 and $\mathrm{hpL} 2$, were morphologically distinct from the BNHS specimens of $F$. brevipalmata and $F$. keralensis, and from the MNHN specimens of
F. nilagirica. Measurements of the museum specimens are given in Appendix 2. In the discriminant analysis using females of $\mathrm{hpL} 1$, $F$. brevipalmata and F. keralensis (Fig. 4A, Table 2), the coefficients for the standardized canonical discriminant function 1 were large for HLL and FEL, and those of function 2 were large for HW and HLL. In the discriminant analysis using females of hpL2, $F$. brevipalmata and F. keralensis (Fig. 4B, Table 2), the coefficients for the standardized canonical discriminant function 1 were large for ELW, HAL and HW, and those of function 2 were large for HL and HAL. The males of hpL2 were also separated clearly from the males of $F$. brevipalmata and $F$. keralensis (Table 2).

In the discriminant analysis using females

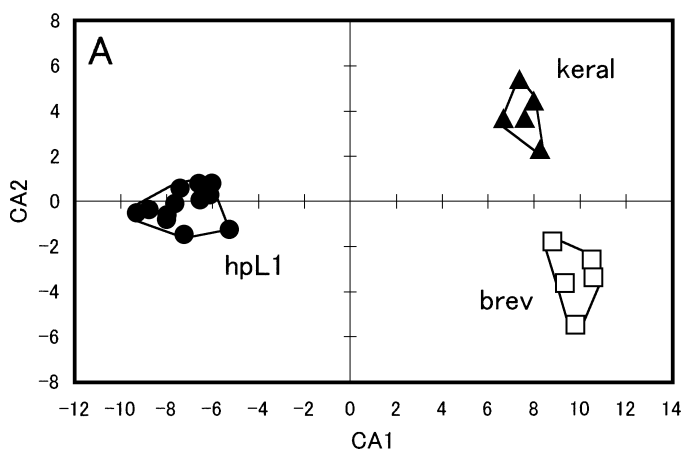

FIG. 4. Scatter plots of individual discriminant scores on the first (CA1) and second canonical axes (CA2) for females of hpL1, F. brevipalamata and F. keralensis (A), and females of hpL2, F. brevipalamata and $F$. keralensis (B).
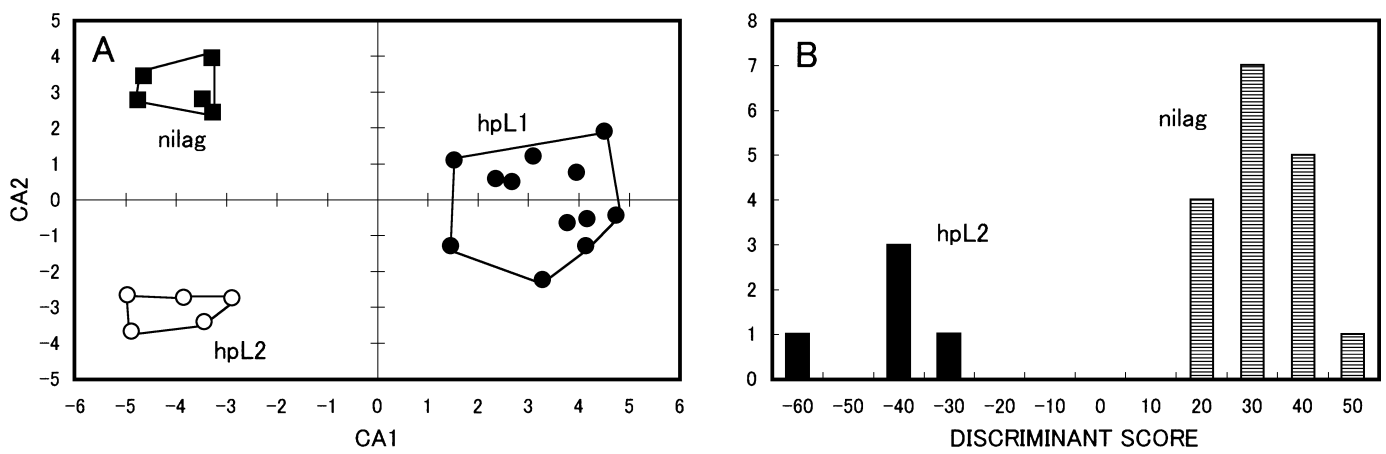

FIG. 5. Scatter plots of individual discriminant scores for females of hpL1, hpL2 and F. nilagirica (A), and frequencies of discriminant scores for males of hpL2 and F. nilagirica (B). 
of hpL1, hpL2 and F. nilagirica (Fig. 5A, Table 2), coefficients for the standardized canonical discriminant function 1 were large for FOL, ELW and FEL, and those for function 2 were large for SVL, F1 and HL. Males of hpL2 were separated clearly from males of $F$. nilagirica as shown in Fig. 5B and Table 2. Coefficients for the standardized canonical function were large for ED, S-N and FOL.

Boulenger (1920) gave measurements of 18 body parts for $F$. brevipalmata $(\mathrm{n}=7), F$. keralensis $(\mathrm{n}=9)$ and $F$. nilagirica $(\mathrm{n}=3)$. Using his measurements, these three species were separated clearly by the discriminant analysis (the eigenvalue for function 1: 170.527; the Wilks' lambda for functions 1-2: <0.001). Although Boulenger's methods for recording measurements differed slightly from ours, the discriminant scores of hpL1 and hpL2 calculated with coefficients from the above analysis indicated that $\mathrm{hpL} 1$ and $\mathrm{hpL} 2$ differed significantly from $F$. brevipalmata, $F$. keralensis and $F$. nilagirica. Thus, it is obvious that hpL1 and $\mathrm{hpL} 2$ differ from each other and also from $F$. brevipalamata, $F$. keralensis and $F$. nilagirica. We have not collected specimens of the latter three species in our study area, so far as the above comparisons are concerned.

From a biometric perspective, hpL1 had larger values for N-E, TD and HAL, and hpL2 is larger in N-N and IMT, as compared to SVL. Fejervarya brevipalmata had a relatively short hindlimb and large inner metatarsal tubercle, whereas $F$. keralensis had a wide head and large tympanum. In addition, $F$. keralensis is readily distinguishable by its wide webbing; the web formula of the BNHS specimens was I1-2II2-1III1/1/2-1IV1-1V. This agrees well with the original description of $F$. keralensis by Günther (1875, as Rana verru$\cos a$ ) that the web is nearly complete.

Of the five small-sized Fejervarya species known to occur in the Western Ghats, four were excluded from detailed biometric comparisons with $\mathrm{hpS} 1$ and $\mathrm{hpS} 2$, because their diagnostic features did not fit the latter two haplotypes. Pillai (1979) described F. murthii (as Rana murthii) from Gudallur, Tamil Nadu, and Daniels (1992) reported its occurrence in the Dakshin Kannad District of Karnataka. The most remarkable diagnostic feature of this species is the presence of two triangular patches bearing pearl-like papillae on the breast in males, and also the presence of the papillae in the anterior part of the lower jaw (Pillai, 1979). We, however, could not find such papillae in hpS1 and hpS2. For the other characteristics of $F$. murthii, some agreed with either hpS1 or hpS2, whereas others agreed with neither of these haplotypes. Thus, it is obvious that hpS1 and hpS2 differ from $F$. murthii.

Fejervarya mysorensis was described by Rao (1922, as Rana limnocharis mysorensis) from Jog, Shimoga District. Because the type locality, Jog, is very close to Talagini where both $\mathrm{hpS} 1$ and $\mathrm{hpS} 2$ occur, there is a possibility that one of the small-bodied haplotypes actually represents $F$. mysorensis. However, description by Rao (1922) of diagnostic features such as "vomerine teeth .... meeting in the median line", "internasal width equals the interorbital space", "fairly big round outer metatarsal tubercle", and "the abdomen is yellow", did not apply to either of the two small-bodied haplotypes. The HLL/ SVL ratio calculated from the measurements of Rao (1922) was far beyond the ratios of hpS1 and hpS2 (1.84 and 2.16 in F. mysorensis, vs. $1.42-1.76$ in $\mathrm{hpS} 1$ and $1.28-1.68 \mathrm{in} \mathrm{hpS} 2$ ). Dutta and Singh (1996), examining the type specimen of $F$. mysorensis in the British Natural History Museum, regarded "eight dark broad bands on the lower lip separated by narrow white vertical band" as unique to this taxon. This did not agree with color pattern in the corresponding portion of $\mathrm{hpS} 1$ or $\mathrm{hpS} 2$. Dubois (1984) treated this taxon as incertae sedis, but Dutta and Singh (1996) considered it to be a valid species.

Fejervarya parambikuramana, described by Rao (1937, as Rana parambikuramana) from Cochin State (now a part of Kerala), is distinct in its smooth dorsum and long hindlimb (the tibio-tarsal articulation reaches far beyond the 

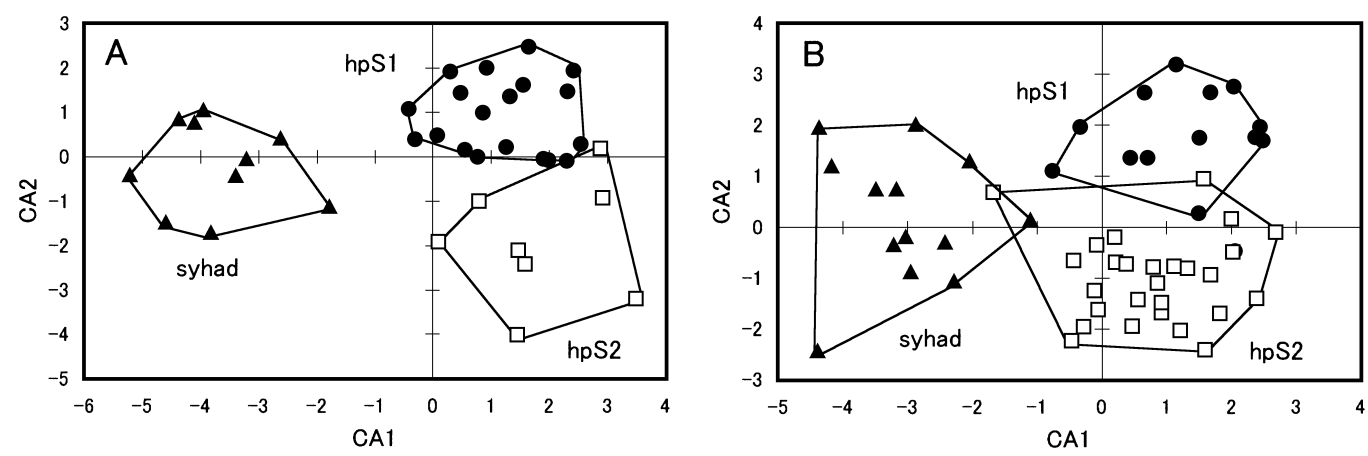

FIG. 6. Scatter plots of individual discriminant scores for females (A) and males (B) of hpS1, hpS2 and $F$. syhadrensis.

tip of the snout). None of our forms characterized by the mtDNA haplotype agreed with this description. This taxon was placed in incertae sedis and the type specimen was reported by Dubois (1984) to have been lost.

Fejervarya sauriceps, also described by Rao (1937, as Rana sauriceps), was based on specimens from Coorg (=Kodagu), Mysore State (now a part of Karnataka). According to the original description, it has a very small tongue, unique triangular pit on the snout, a brown venter and wide interorbital width (more than twice the upper eyelid width), which disagreed with $\mathrm{hpS} 1$ and $\mathrm{hpS} 2$. This taxon was placed in incertae sedis and the type specimen has been lost according to Dubois (1984).

Fejervarya syhadrensis was described by Annandale (1919, as Rana limnocharis syhadrensis) from the Poona District, Maharashtra. The original description was very brief and detailed descriptions by Anders (2002) and Chanda (2002) suggested that this taxon may fit either hpS1 or hpS2. Thus, we made a detailed comparison of measurements from $\mathrm{hpS1}, \mathrm{hpS} 2$ and museum specimens of $F$. syhadrensis.

Results of the discriminant analysis involving the MNHN specimens of $F$. syhadrensis are shown in Fig. 6. In the analysis using females of hpS1, hpS2 and $F$. syhadrensis (Fig. 6A, Table 2), coefficients for the standardized canonical discriminant function 1 were large for TIL, FEL and SVL. In the analysis using male specimens (Fig. 6B, Table 2 ), coefficients for the standardized canonical discriminant function 1 were large for TIL and HAL.

Boulenger (1920) gave measurements from two specimens of $F$. syhadrensis, and their discriminant scores (calculated from the discriminant coefficients using 10 measurements for females of hpS1 and $\mathrm{hpS} 2$ ) were much larger positive values than those of $\mathrm{hpS} 1$.

To examine differences in body proportions, all measurements exclusive of SVL were transformed into ratios to SVL (i. e., HL/SVL, HW/SVL, and so on), and compared by MannWhitney U-tests among the large-bodied taxa (hpL1, hpL2, F. brevipalmata, F. keralensis, and $F$. nilagirica) and also among the smallbodied taxa (hpS1, hpS2, and F. syahadrensis). The results revealed significant differences in various body proportions, although in most ratios ranges overlapped between samples compared (Table 3). For example, females of hpL1 had relatively long phalanges compared with females of hpL2; in F3/SVL, F4/SVL, $\mathrm{T} 1 / \mathrm{SVL}$, and T2/SVL, the differences were significant at the $1 \%$ level. Similarly, in both females and males, hpS1 had a relatively large head as compared with hpS2, with differences in HL/SVL and HW/SVL being significant at the $1 \%$ level in females and 5\% level in males. Significant differences in ratios were observed in comparisons with $F$. brevipalmata, $F$. keralensis, $F$. nilagirica, and $F$. syhadrensis. Because of considerable extents of range- 
TABLE 3. Comparisons of body ratios between Fejervarya species and haplotypes. Symbols * and ** indicate the $5 \%$ and $1 \%$ levels of significance, respectively. Abbreviations brev, keral, nilag and syhad refer to $F$. brevipalmata, F. keralensis, $F$. nilagirica and $F$. syhadrensis, respectively.

\begin{tabular}{lll}
\hline \multirow{2}{*}{ Ratio } & Taxa compared & $\mathrm{P}$ \\
\cline { 2 - 3 } & Mean (Range) $\quad$ Mean (Range)
\end{tabular}

(Large-type taxa)

hpL1 female vs. hpL2 female

HW/SVL $0.330(0.305-0.350) \quad 0.313(0.299-0.326) \quad 0.020^{*}$ $\mathrm{ED} / \mathrm{SVL} \quad 0.105(0.088-0.124) \quad 0.090(0.083-0.104) \quad 0.015 *$ $\begin{array}{llll}\text { ELW/SVL } & 0.086(0.080-0.094) & 0.078(0.075-0.082) & 0.008^{* *}\end{array}$ TD/SVL $\quad 0.070(0.058-0.078) \quad 0.059(0.050-0.069) \quad 0.015^{*}$ HAL/SVL $0.247(0.218-0.273) \quad 0.218(0.205-0.236) \quad 0.008^{* *}$ F3/SVL $\quad 0.152(0.137-0.163) \quad 0.118(0.111-0.131) \quad 0.002^{* *}$ F4/SVL $\quad 0.099(0.084-0.113) \quad 0.081(0.070-0.089) \quad 0.006^{* *}$ $\mathrm{T} 1 / \mathrm{SVL} \quad 0.103(0.085-0.119) \quad 0.085(0.078-0.096) \quad 0.006^{* *}$ T2/SVL $\quad 0.201(0.168-0.234) \quad 0.167(0.150-0.188) \quad 0.008^{* *}$ $\begin{array}{llll}\mathrm{T} 5 / \mathrm{SVL} & 0.307(0.279-0.336) & 0.276(0.239-0.313) & 0.035 *\end{array}$ HL/HW $0.903(0.808-0.981) \quad 1.007(0.923-1.065) \quad 0.020^{*}$

hpL1 female vs. brev female

HW/SVL $0.330(0.305-0.350) \quad 0.302(0.285-0.323)$ N-E/SVL $\quad 0.095(0.076-0.113) \quad 0.080(0.066-0.098)$ ED/SVL $\quad 0.105(0.088-0.124) \quad 0.096(0.089-0.101)$ E-E/SVL $\quad 0.055(0.045-0.070) \quad 0.066(0.061-0.072)$ TD/SVL $\quad 0.070(0.058-0.078) \quad 0.062(0.050-0.069)$ HAL/SVL $0.247(0.218-0.273) \quad 0.216(0.192-0.232)$ IMT/SVL $0.043(0.033-0.057) \quad 0.064(0.048-0.077)$ N-N/E-E $\quad 1.547(1.394-1.838) \quad 1.401(1.344-1.536)$ ELW/E-E $1.588(1.242-2.027) \quad 1.214(1.048-1.352)$

$\mathrm{hpL1}$ female vs. keral female

HW/SVL $\quad 0.330(0.305-0.350) \quad 0.377(0.350-0.419)$ E-E/SVL $\quad 0.055(0.045-0.070) \quad 0.067(0.057-0.076)$ ELW/SVL $0.086(0.080-0.094) \quad 0.096(0.084-0.111)$ TD/SVL $\quad 0.070(0.058-0.078) \quad 0.083(0.075-0.097)$ TIL/SVL $\quad 0.547(0.489-0.584) \quad 0.595(0.521-0.657)$ IMT/SVL $\quad 0.043(0.033-0.057) \quad 0.062(0.051-0.075)$ $\mathrm{TD} / \mathrm{ED} \quad 0.666(0.557-0.756) \quad 0.752(0.651-0.870)$ FOL/FEL $1.159(1.053-1.252) \quad 1.055(1.020-1.073)$

hpL1 female vs. nilag female

HL/SVL $\quad 0.298(0.252-0.338) \quad 0.270(0.259-0.282)$ HW/SVL $\quad 0.330(0.305-0.350) \quad 0.309(0.296-0.326)$ S-N/SVL $\quad 0.083(0.074-0.098) \quad 0.072(0.063-0.082)$ N-E/SVL $\quad 0.095(0.076-0.113) \quad 0.073(0.064-0.085)$ ELW/SVL $0.086(0.080-0.094) \quad 0.079(0.071-0.089)$ HAL/SVL $0.247(0.218-0.273) \quad 0.213(0.197-0.225)$ F1/SVL $\quad 0.129(0.102-0.150) \quad 0.114(0.101-0.124)$ F2/SVL $\quad 0.106(0.089-0.126) \quad 0.091(0.085-0.099)$ HLL/SVL $1.740(1.593-1.830) \quad 1.621(1.561-1.681)$

$0.015^{*}$ $0.020^{*}$ $0.004 * *$ $0.045^{*}$ $0.003^{* *}$ $0.035^{*}$ $0.006^{* *}$ $0.020^{*}$ $0.020^{*}$ $0.020 *$ $0.002 * *$ $0.027^{*}$ $0.003^{* *}$ $0.020 *$ $0.008^{* *}$ $0.008^{* * *}$
FEL/SVL $0.502(0.445-0.548)$

$0.464(0.443-0.479)$ TIL/SVL $\quad 0.547(0.489-0.584) \quad 0.504(0.497-0.511)$ FOL/SVL $0.580(0.534-0.631) \quad 0.538(0.517-0.567)$ $0.027^{*}$ $0.008^{* * *}$ hpL2 female vs. brev female

N-N/E-E $1.560(1.378-1.783) \quad 1.401(1.344-1.536) \quad 0.047 *$ hpL2 female vs. keral female

HW/SVL $\quad 0.313(0.299-0.326) \quad 0.377(0.350-0.419)$ ED/SVL $\quad 0.090(0.083-0.104) \quad 0.110(0.096-0.119)$ ELW/SVL $\quad 0.078(0.075-0.082) \quad 0.096(0.084-0.111)$ TD/SVL $\quad 0.059(0.050-0.069) \quad 0.083(0.075-0.097)$ HL/HW $1.007(0.923-1.065) \quad 0.851(0.809-0.886)$ FOL/FEL $1.186(1.078-1.271) \quad 1.055(1.020-1.073)$ hpL2 female vs. nilag female

HL/SVL $\quad 0.315(0.276-0.337) \quad 0.270(0.259-0.282)$ TIL/SVL $\quad 0.571(0.547-0.603) \quad 0.504(0.497-0.511)$ FOL/SVL $0.583(0.544-0.614) \quad 0.538(0.517-0.567)$ HL/HW $1.007(0.923-1.065) \quad 0.873(0.818-0.922)$ hpL 2 male vs. brev male

N-E/SVL $\quad 0.086(0.072-0.097) \quad 0.071(0.060-0.077) \quad 0.006^{* *}$ F2/SVL $\quad 0.094(0.082-0.108) \quad 0.105(0.100-0.112) \quad 0.007 * *$ HLL/SVL $1.723(1.563-1.849) \quad 1.601(1.519-1.740) \quad 0.049 *$ hpL2 male vs. keral male

HW/SVL $\quad 0.344(0.313-0.365) \quad 0.378(0.347-0.409)$ N-E/SVL $\quad 0.086(0.072-0.097) \quad 0.100(0.088-0.114)$ $\mathrm{ED} / \mathrm{SVL} \quad 0.104(0.094-0.119) \quad 0.123(0.112-0.135)$ ELW/SVL $0.084(0.063-0.100) \quad 0.115(0.103-0.131)$ TD/SVL $\quad 0.057(0.040-0.072) \quad 0.086(0.071-0.100)$ HAL/SVL $0.221(0.198-0.245) \quad 0.249(0.230-0.281)$ F1/SVL $\quad 0.119(0.094-0.142) \quad 0.147(0.142-0.157)$ F2/SVL $\quad 0.094(0.082-0.108) \quad 0.108(0.089-0.131)$ $\mathrm{HL} / \mathrm{HW} \quad 0.914(0.794-0.959) \quad 0.820(0.698-0.934)$ $\mathrm{TD} / \mathrm{ED} \quad 0.548(0.375-0.658) \quad 0.709(0.528-0.868)$ ELW/E-E $1.435(1.049-1.709) \quad 1.927$ (1.483-2.498)

hpL2 male vs. nilag male

$\begin{array}{ll}0.079(0.068-0.095) & 0.046^{*} \\ 0.084(0.074-0.092) & 0.007^{* *} \\ 0.075(0.065-0.092) & 0.046^{*} \\ 0.097(0.088-0.105) & 0.046^{*} \\ 0.239(0.222-0.253) & 0.021^{*} \\ 1.284(1.207-1.478) & 0.004^{* *} \\ 1.203(0.960-1.348) & 0.026^{*}\end{array}$

(Small-type taxa)

hpS1 female vs. hpS2 female

HL/SVL $0.311(0.281-0.339) \quad 0.281(0.254-0.319)$ HW/SVL $\quad 0.338(0.302-0.377) \quad 0.311(0.293-0.339)$ $0.005^{* *}$ $0.009 * *$ N-N/SVL $\quad 0.095(0.076-0.116) \quad 0.084(0.071-0.091) \quad 0.008^{* *}$ ELW/SVL $0.088(0.075-0.106) \quad 0.083(0.080-0.089) \quad 0.050^{*}$ FAL/SVL $0.413(0.364-0.454) \quad 0.385(0.357-0.411) \quad 0.013^{*}$ T2/SVL $\quad 0.184(0.127-0.241) \quad 0.149(0.101-0.202) \quad 0.030^{*}$ $\mathrm{T} 3 / \mathrm{SVL} \quad 0.271(0.207-0.318) \quad 0.243(0.209-0.283) \quad 0.038^{*}$ 
TABLE 3. Extended

\begin{tabular}{|c|c|c|c|}
\hline \multicolumn{4}{|c|}{ hpS1 female vs. syhad female } \\
\hline HL/SVL & $0.311(0.281-0.339)$ & $0.294(0.278-0.314)$ & $0.015^{*}$ \\
\hline HW/SVL & $0.338(0.302-0.377)$ & $0.307(0.266-0.341)$ & $0.001 * *$ \\
\hline N-E/SVL & $0.097(0.082-0.111)$ & $0.082(0.074-0.092)$ & $0.001 * *$ \\
\hline $\mathrm{ED} / \mathrm{SVL}$ & $0.108(0.093-0.122)$ & $0.091(0.075-0.105)$ & $0.001 * *$ \\
\hline ELW/SVL & $0.088(0.075-0.106)$ & $0.076(0.066-0.080)$ & $0.001^{* *}$ \\
\hline $\mathrm{HAL} / \mathrm{SVL}$ & $0.240(0.191-0.293)$ & $0.206(0.179-0.233)$ & $0.001^{* *}$ \\
\hline F1/SVL & $0.116(0.096-0.137)$ & $0.104(0.077-0.121)$ & $0.025^{*}$ \\
\hline $\mathrm{F} 2 / \mathrm{SVL}$ & $0.103(0.085-0.133)$ & $0.091(0.071-0.102)$ & $0.025^{*}$ \\
\hline FOL/SVL & $0.523(0.475-0.569)$ & $0.496(0.448-0.539)$ & $0.017^{*}$ \\
\hline TD/ED & $0.566(0.363-0.759)$ & $0.717(0.552-1.097)$ & $0.006^{* *}$ \\
\hline S-N/N-E & $0.846(0.729-1.116)$ & $0.948(0.778-1.111)$ & $0.019 *$ \\
\hline ELW/E-E & $1.290(0.971-1.690$ & $1.089(0.897-1.400)$ & \\
\hline \multicolumn{4}{|c|}{ hpS2 female vs. syhad female } \\
\hline ED/SVL & $0.106(0.085-0.121)$ & $0.091(0.075-0.105)$ & $0.021 *$ \\
\hline ELW/SVL & $0.083(0.080-0.089)$ & $0.076(0.066-0.080)$ & $0.005^{* *}$ \\
\hline $\mathrm{HAL} / \mathrm{SVL}$ & $0.229(0.196-0.256)$ & $0.206(0.179-0.233)$ & $0.016^{*}$ \\
\hline LW/E-E & $1.242(1.124-1.379)$ & $1.089(0.897-1.400)$ & $0.033^{*}$ \\
\hline \multicolumn{4}{|c|}{ hpS1 male vs. hpS2 male } \\
\hline HL/SVL & $0.308(0.256-0.352)$ & $0.291(0.259-0.334)$ & $0.039^{*}$ \\
\hline HW/SVL & $0.346(0.313-0.384)$ & $0.329(0.304-0.379)$ & $0.017 *$ \\
\hline FEL/SVL & $0.458(0.416-0.498)$ & $0.434(0.356-0.480)$ & $0.042 *$ \\
\hline TIL/SVL & $0.500(0.457-0.566)$ & $0.476(0.420-0.515)$ & $0.048^{*}$ \\
\hline T1/SVL & $0.092(0.065-0.116)$ & $0.081(0.058-0.103)$ & $0.026^{*}$ \\
\hline T2/SVL & $0.180(0.147-0.205)$ & $0.159(0.113-0.198)$ & $0.005^{* *}$ \\
\hline T5/SVL & $0.269(0.218-0.296)$ & $0.255(0.202-0.307)$ & $0.039^{*}$ \\
\hline IMT/SVL & $0.043(0.034-0.055)$ & $0.038(0.031-0.054)$ & $0.019 *$ \\
\hline TD/ED & $0.549(0.416-0.701)$ & $0.625(0.435-0.855)$ & $0.048^{*}$ \\
\hline FOL/FEL & $1.100(0.995-1.200)$ & $1.180(1.038-1.359)$ & $0.005^{* *}$ \\
\hline \multicolumn{4}{|c|}{ hpS1 male vs. syhad male } \\
\hline HW/SVL & $0.346(0.313-0.384)$ & $0.325(0.287-0.364)$ & $0.011 *$ \\
\hline N-E/SVL & $0.095(0.078-0.105)$ & $0.087(0.070-0.110)$ & $0.011 *$ \\
\hline $\mathrm{ED} / \mathrm{SVL}$ & $0.112(0.101-0.124)$ & $0.105(0.088-0.129)$ & $0.011 *$ \\
\hline TD/SVL & $0.061(0.050-0.079)$ & $0.073(0.051-0.108)$ & $0.004 * *$ \\
\hline $\mathrm{HAL} / \mathrm{SVL}$ & $0.240(0.210-0.270)$ & $0.212(0.191-0.262)$ & $0.001 * *$ \\
\hline $\mathrm{F} 2 / \mathrm{SVL}$ & $0.099(0.082-0.120)$ & $0.090(0.064-0.112)$ & $0.048^{*}$ \\
\hline $\mathrm{TD} / \mathrm{ED}$ & $0.549(0.416-0.701)$ & $0.698(0.517-1.036)$ & $0.001^{* *}$ \\
\hline ELW/E-E & $1.299(0.958-1.838)$ & $1.096(0.571-1.375)$ & $0.019 *$ \\
\hline TIL/FEL & $1.092(0.981-1.190)$ & $1.133(1.039-1.206)$ & $0.025^{*}$ \\
\hline \multicolumn{4}{|c|}{ hpS2 male vs. syhad male } \\
\hline N-E/SVL & $0.093(0.072-0.112)$ & $0.087(0.070-0.110)$ & $0.037^{*}$ \\
\hline E-E/SVL & $0.067(0.053-0.076)$ & $0.077(0.052-0.103)$ & $0.001 * *$ \\
\hline $\mathrm{HAL} / \mathrm{SVL}$ & $0.228(0.196-0.250)$ & $0.212(0.191-0.262)$ & $0.001 * *$ \\
\hline $\mathrm{F} 2 / \mathrm{SVL}$ & $0.099(0.075-0.119)$ & $0.090(0.064-0.112)$ & $0.013^{*}$ \\
\hline TIL/SVL & $0.476(0.420-0.515)$ & $0.512(0.459-0.561)$ & $0.001^{* *}$ \\
\hline N-N/E-E & $1.439(1.043-1.779)$ & $1.304(0.857-1.938)$ & $0.023^{*}$ \\
\hline ELW/E-E & $1.270(0.990-1.669)$ & $1.096(0.571-1.375)$ & $0.009 * *$ \\
\hline TIL/FEL & $1.100(0.994-1.204)$ & $1.133(1.039-1.206)$ & $0.049 *$ \\
\hline FOL/FEL & $1.180(1.038-1.359)$ & $1.080(0.838-1.271)$ & $0.005^{* *}$ \\
\hline
\end{tabular}

overlaps in most pair-wise comparisons of samples, however, these differences cannot be regarded as absolutely diagnostic. Ranges did not overlap at all in the following combinations: HW/SVL of female hpL1 and $F$. keralensis; HW/SVL of female hpL2 and $F$. keralensis; ELW/SVL of female hpL2 and $F$. keralensis; ELW/SVL of female hpS2 and $F$. syhadrensis; TD/SVL of female hpL2 and $F$. keralensis; F1/SVL of male hpL2 and $F$. keralensis; F3/SVL of female hpL1 and hpL2; and TIL/SVL of female hpL2 and $F$. nilagirica.

The same was true for the ratios $\mathrm{HL} / \mathrm{HW}$, S-N/N-E, TD/ED, N-N/E-E, ELW/E-E F1/ F2, TIL/FEL and FOL/FEL (Table 3). Females of hpL1 had smaller HL/HW than female hpL2, larger N-N/E-E and ELW/E-E than female $F$. brevipalmata, and smaller TD/ED than female $F$. keralensis. Males of hpS1 had smaller TD/ED and FOL/FEL than male $\mathrm{hpS} 2$ and the latter had larger ELW/E-E and larger FOL/FEL than male $F$. syhadrensis. Males of hpL2 differed significantly from male F. keralensis in HL/HW, TD/ED and ELW/ $\mathrm{E}-\mathrm{E}$, and from male $F$. nilagirica in N-N/E-E and ELW/E-E, and so on. In most of these comparisons where there were significant differences, however, ranges of ratios showed overlap to some extent between samples compared. Ranges did not overlap in HL/HW between female hpL2 and $F$. keralensis, in $\mathrm{HL} / \mathrm{HW}$ between female hpL2 and $F$. nilagirica, and in FOL/FEL between female hpL2 and $F$. keralensis.

From these analyses, we conclude that the four haplotypes are distinct from each other and from all previously described species. We therefore name each of these haplotypes as a new species. All of the type specimens, deposited in BNHS, were subjected to mtDNA sequencing. To facilitate future molecular comparisons among these morphologically confusing species, accession numbers of mtDNA sequence data from the type specimens are given in Appendix 3. 


\section{SPECIES ACCOUNTS}

\section{Fejervarya mudduraja sp. nov.}

(Figs. 7A and 8A, Table 1)

Large haplotype 1 (hpL1) in the above comparisons

Fejervarya cf. brevipalmata in Kurabayashi et al. (2005).

\section{Diagnosis}

A large Fejervarya species, mean SVL of females being $45 \mathrm{~mm}$. Longitudinal dermal ridges on the back are relatively long and tend to be arranged into four longitudinal lines. On average, the inner metatarsal tubercle relative to SVL is smaller than in F. brevipalmata and $F$. keralensis; the hindlimb, foot and hand are longer than those of $F$. nilagirica; and the hand, fingers and toes are longer than in $\mathrm{hpL} 2$, which is described below as another new spe-
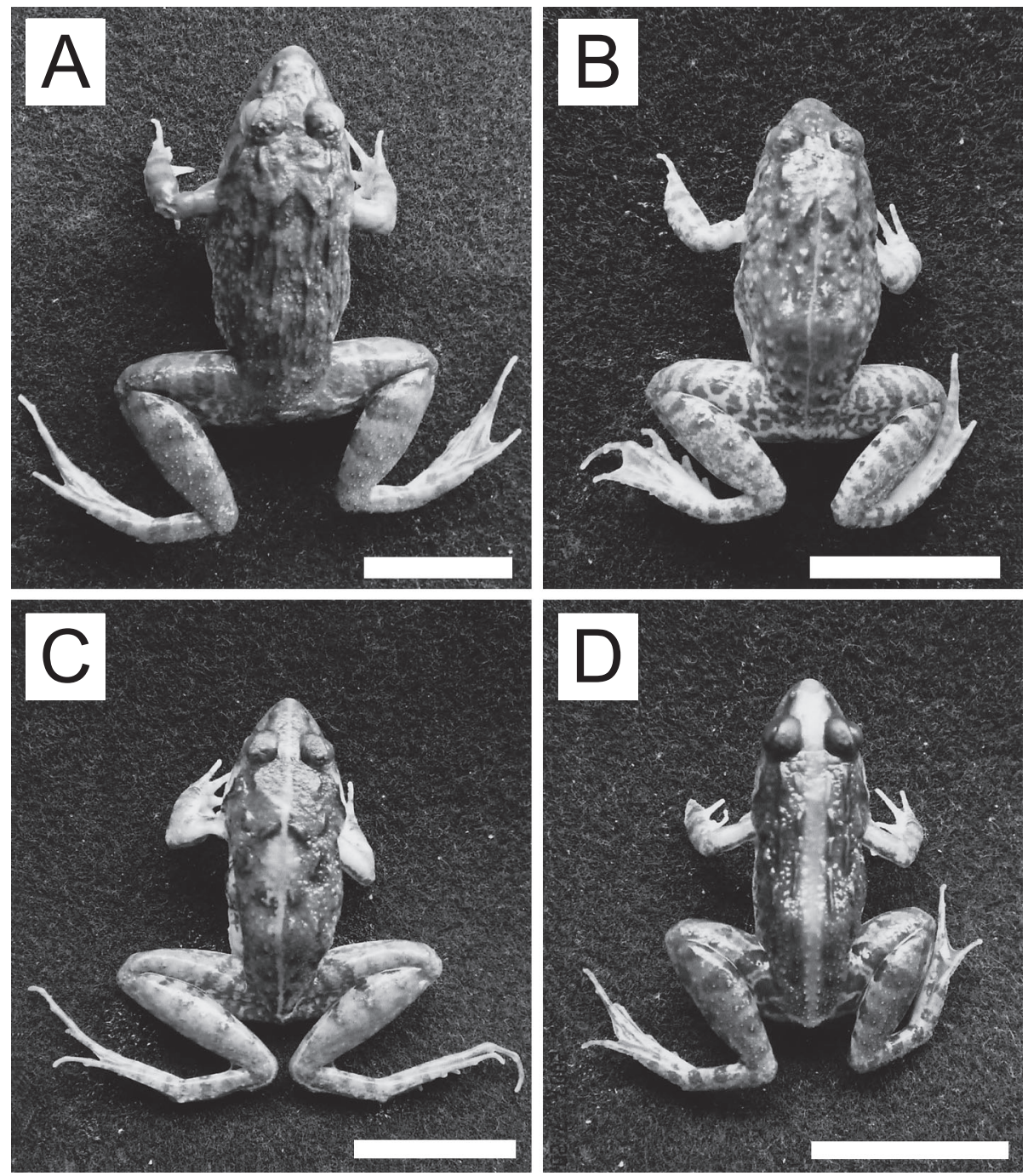

FIG. 7. Fejervarya mudduraja (A: holotype BNHS 4645), F. granosa (B: holotype BNHS 4649), F. kudremukhensis (C: holotype BNHS 4653), and F. caperata (D: holotype BNHS 4657). Scale $2 \mathrm{~cm}$. 

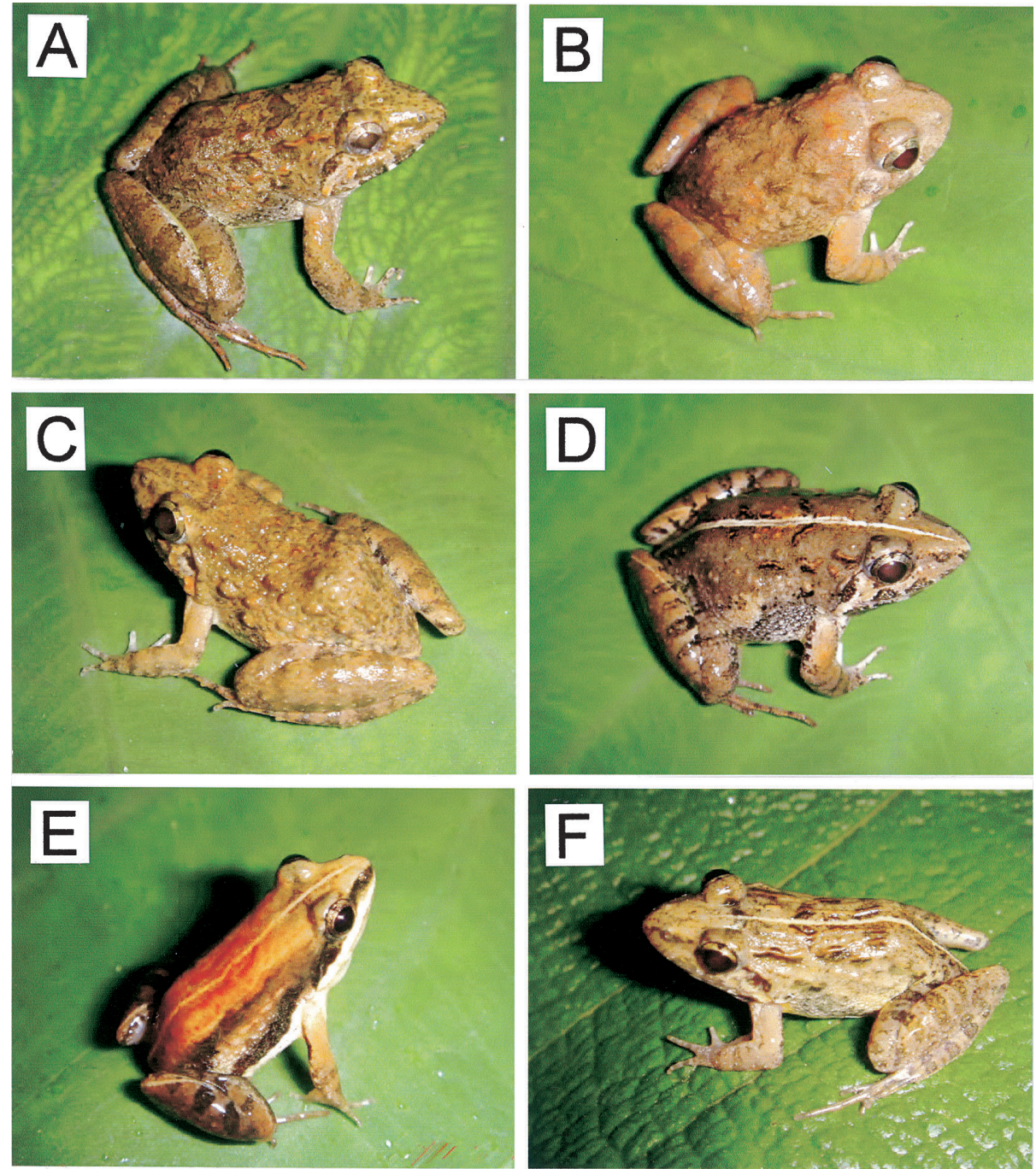

FIG. 8. Six Fejervarya species in central Western Ghats. A. F. mudduraja from Talapu, Madikeri (paratype BNHS 4647). B. F. rufescens from Aralam (RBRL 05071405). C. F. granosa from Talagini (paratype BNHS 4650). D. F. kudremukhensis from Mudigere (paratype BNHS 4656). E. F. sahyadris from Aralam (RBRL 05071402). F. F. caperata from Bajipe, Mangalore (paratype BNHS 4658).

cies. Head width and tympanum, both relative to SVL, are smaller than in F. keralensis. Eyelid width relative to inter-orbital distance is larger than in $F$. brevipalmata (Table 3).

\section{Holotype}

BNHS 4645, female collected from Talapu, Madikeri, on 17 July 2004. SVL: $50.7 \mathrm{~mm}$.

\section{Paratypes}

BNHS 4646, female collected from Made, Madikeri, on 7 June 2003. SVL: $50.5 \mathrm{~mm}$. BNHS 4647, female collected from Talapu, Madikeri, on 17 July 2004. SVL: $43.8 \mathrm{~mm}$. BNHS 4648, female collected from Mudigere on 9 July 2005 . SVL: $51.8 \mathrm{~mm}$. 
Description of holotype (measurements in $\mathrm{mm}$ )

Vomerine teeth in two oblique lines between choanae, beginning at level of anterior border of choanae, extending beyond its posterior border; tongue wide, with two projections at tip.

Head wider than long (HL: 14.7; HW: 16.1); snout more or less pointed from above; loreal region strongly concave; canthus rostralis not sharp; nostril nearer to snout than to eye (S-N: 4.0; N-E: 5.0); inter-narial distance greater than inter-orbital distance (N-N: 3.9; E-E: 2.4), the latter narrower than upper eyelid (ELW: 4.0); tympanum distinct, its diameter about $60 \%$ of eye diameter (ED: 5.2; TD: 3.3).

Fingers free; finger tip rounded; finger lengths $4<2<1<3$ (F1: 6.3; F2: 5.5; F3: 7.5; F4: 4.9); subarticular and palmar tubercles well developed; thenal tubercle large.

Hind limb not much long (HLL/SVL: 1.59); tibia longer than femur (FEL: 22.6; TIL: 24.8); toe lengths $1<2<5<3<4$ (T1: 4.9; T2: 9.5; T3: 14.4; T4: 20.0; T5: 14.2); toe tip rounded; subarticular tubercles moderate; inner metatarsal tubercle long and laterally compressed (IMT: 1.6); outer metatarsal tubercle small (OMT: 0.9); webs I2-2II 12/3-2 $\frac{1}{2}$ IIII2-3IV2-1 1/2V; web between third and fourth toes, and that between fourth and fifth toes, strongly incised, the latter extending to the bases of metatarsals, the others to middle portions of metatarsals; dermal ridge along outer edge of fifth toe.

Indistinct dermal granules on snout; small tubercles on upper eyelid; dorsum with many long and short dermal ridges; interrupted inverse V-shaped ridge on center of dorsum at level of forelimbs; from both postero-lateral ends of this ridge stretching posteriorly more or less distinct longitudinal ridges; another pair of longitudinal ridges running from upper eyelid to posterior direction; supra-tympanic fold distinct; lateral sides granular; outer edge of forearm with a few granules; anterodorsal part of thigh, anal region, dorsal surface of tibia, and tarsus with small granules; ventral side smooth.

In preservative, dark brown above; dark inverse V-shaped marking inside interrupted inverse V-shaped ridge; large pale-brown marking behind the above marking; pale streak from behind eye through antero-ventral part of tympanum to base of forelimb; relatively broad dark bands connecting upper and lower jaws; cross bars on anterior part of thigh; posterior surface of thigh marbled; cross bars on tibia, tarsus and foot; ventral side of body white; ventral sides of hand and foot dark brown with pale tubercles; throat with several weak longitudinal stripes.

\section{Variation}

Some specimens examined had a large dark $\mathrm{V}$-shaped marking connecting the upper eyelids and a W-shaped marking behind the inverse V-shaped ridge on the back. Distinct or weak marking occured on the throat in some specimens. Two paratypes (BNHS 4646 and BNHS 4648) had a broad mid-dorsal stripe and two other specimens had a narrow mid-dorsal stripe among a total of 18 specimens examined. In some specimens, the two components of the interrupted inverse V-shaped ridges were separated rather widely and were almost parallel to each other. In many specimens, the inverse Vshaped ridges was not as distinct as in the holotype. The paratype (BNHS 4648) had a thin tibio-tarsal stripe that runs from the inner central portion of the tibia through the ankle to the outer base of the tarsus. Because all three male specimens were juveniles, male sexual characters remain uncertain.

\section{Etymology}

Named after Muddu Raja of the Haleri Dynasty, who founded Madikeri (Mercara), the type locality of this species, in the late $17 \mathrm{th}$ Century.

\section{Notes}

We collected this species in Madikeri and Mudigere. They were found in wetlands and among roadside bushes along with hpL2 described below, but never in paddy fields. 
Fejervarya rufescens (Jerdon, 1854 “1853”)

(Fig. 8B; Table 1)

Pyxicephalus rufescens Jerdon, 1854 "1853". J. Asiat. Soc. Bengal 22: 534. Type-locality: Malabar.

The original description by Jerdon (1853) was very brief and detailed descriptions were given by Boulenger $(1890,1920)$. The robust reddish body, rounded snout, rounded dorsal ridges, and large compressed inner metatarsal tubercle diagnose this species very clearly. Measurements of the MNHN specimens of F. rufescens, including the neotype, are given in Appendix 2.

\section{Variation}

Mature males had a dark M-shaped marking on the throat with a wide white longitudinal band from the tip of the lower jaw to the concaved portion of the M-marking. No long dermal ridges and no mid-dorsal stripe occurred.

\section{Call structure}

Kadadevaru et al. (2000) reported call structures of this species (as Tomopterna rufescens). The call is composed of pulse groups, each consisting of about 50 pulses, $0.24 \mathrm{~s}$ in duration. The frequency range is wide and the dominant band is at about $3 \mathrm{kHz}$.

\section{Notes}

Boulenger (1920) regarded this taxon as connecting the genera Rana and Tomopterna, and some authors (e. g. Chanda, 2002; Daniel, 2002) used the combination, Tomopterna rufescens or Sphaeroteca rufescens. Our results from mtDNA sequencing (Kurabayashi et al., 2005) revealed unequivocally that this taxon is a member of Fejervarya with no direct relationship to Sphaeroteca as already emphasized by Dubois (1984). There was a considerable genetic divergence between $F$. rufescens populations from Karnataka and Kerala (our unpublished data).

We collected $F$. rufescens on the ground or in wetlands, but not in paddy fields. Our collection localities are Mangalore (Bajipe, Padil), Talagini, Karnoor, and Aralam.
Fejervarya granosa sp. nov.

(Figs. 7B, 8C and 9A; Table 1)

Small haplotype 1 (hpS1) in the above comparisons.

Fejervarya sp. (hpA) in Kurabayashi et al. (2005).

\section{Diagnosis}

A small Fejervarya species, mean SVL being $31 \mathrm{~mm}$ in females and $29 \mathrm{~mm}$ in males. Dermal ridges on the back are generally short or rounded and body shape is relatively thick as compared with long ridges and more slender body shape of $\mathrm{hpS} 2$, which is described below as another new species. On average, head width and hand length, both relative to SVL, are larger and tympanum relative to eye diameter is smaller than in F. syhadrensis. Head length and head width, relative to SVL, are larger than in hpS2 (Table 3). Advertisement calls are a series of notes without distinct pulses.

\section{Holotype}

BNHS 4649, female collected from Talapu, Madikeri, on 16 July 2004. SVL: 35.9 mm.

\section{Paratypes}

BNHS 4650, female collected from Talagini on 23 July 2004. SVL: $30.0 \mathrm{~mm}$. BNHS 4651, male collected in Mudigere on 9 July 2005. SVL: $32.9 \mathrm{~mm}$. BNHS 4652, male collected in Talapu, Madikeri, on 9 July 2006. SVL: $29.1 \mathrm{~mm}$.

\section{Description of holotype (measurements in $\mathrm{mm}$ )}

Vomerine teeth rather thick, elliptical, forming slightly oblique series between choanae; head wider than long (HL: 10.5; HW: 12.4); snout moderately pointed; loreal region concave; canthus rostralis blunt; nostril slightly nearer to tip of snout than to eye (S-N: $2.9 ; \mathrm{N}$ $\mathrm{E}: 3.1)$; inter-narial distance greater than interorbital distance (N-N: 3.4; E-E: 2.8), the latter nearly equal to upper eyelid width (ELW: 2.9); tympanum distinct, about $55 \%$ of eye in diameter (ED: 4.0; TD: 2.3).

Finger tip rounded; finger lengths $4<2<1<3$ 

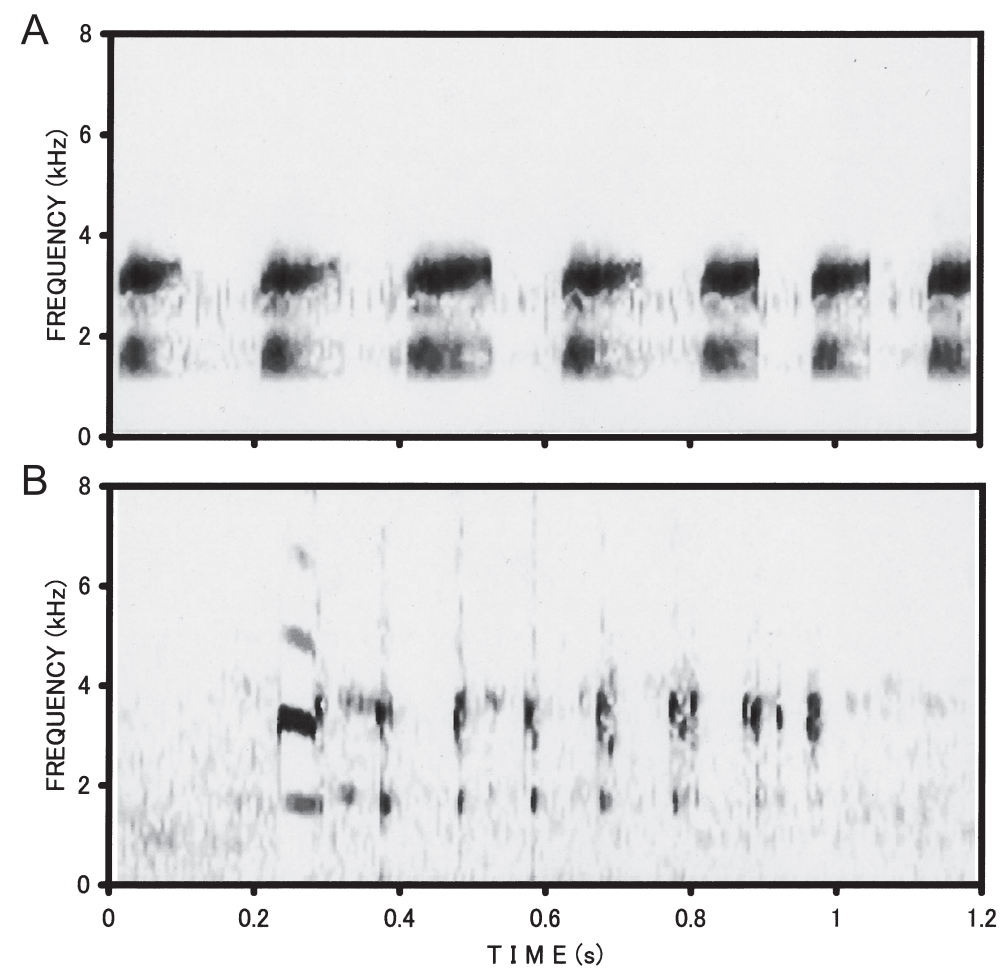

FIG. 9. Sound spectrograms of the advertisement calls of $F$. granosa (A) and F. kudremukhensis (B) (FlatTop window, $323 \mathrm{~Hz}$ bandwidth).

(F1: 4.6; F2: 4.3; F3: 5.6; F4: 3.8); subarticular tubercle well developed.

Hindlimb moderately long (HLL/SVL: 1.68); tibia longer than femur (FEL: 17.3; TIL: 19.3); toe lengths $1<2<3<5<4$ (T1: 3.4; T2: 6.7; T3: 10.0; T4: 13.8; T5: 10.6); subarticular tubercle moderate; webs $\mathrm{I} 1^{2} / 3-2 \mathrm{II} 1 \frac{1}{2}-2 \frac{1}{2} \mathrm{III} 1 \frac{1}{2}-2 \frac{1}{2} \mathrm{IV} 2-$ $1 \mathrm{~V}$; web between fourth and fifth toes extending to bases of metatarsals, the others to middle portions of metatarsals; inner metatarsal tubercle small (IMT: 1.3); dermal fold on outer edge of fifth toe and inner edge of tarsus.

Indistinct granules on eyelid and snout; dorsum covered with relatively large round or elliptical ridges; interrupted inverse V-shaped ridge in middle of dorsum at level of forelimb; supra-tympanic fold distinct; lateral sides with a few granules; upper side of femur relatively smooth; upper side of tibia with a few granules.

In preservative, dorsum dark brown with irregular blotches and a narrow mid-dorsal stripe; round dark-red marking on dorsum at level of forelimbs; irregular black stripe on latero-ventral side; pale band from posterior corner of eye through antero-lower part of tympanum to shoulder; irregular cross bands on forelimb; cross bars on dorsal side of femur; marbled pattern on posterior side of femur; cross bars on tibia distinct; ventral sides of body and limbs white.

\section{Variation}

Many of the specimens examined lacked a round red marking on the back. The pattern on the femur was variable. In males, a conspicuous black marking was present on the throat. An interrupted inverse V-shaped ridge, found in many Fejervarya species, was indistinct. Of the 63 specimens examined, 37 were striped, whereas the remaining 26 were not; in only three of the former, the mid-dorsal stripe was broad. 


\section{Call structure}

Advertisement calls (Fig. 9A) were recorded at Mudigere on 9 July 2005 at an air temperature of $21 \mathrm{C}$. The call was a series of notes that were repeated slowly at the beginning, but were gradually varied to the fast-repeating climax. The note interval at climax was $0.186 \pm$ $0.027 \mathrm{~s}(\overline{\mathrm{x}} \pm \mathrm{SD}, \mathrm{n}=23)$ and the note duration was $0.094 \pm 0.013 \mathrm{~s}$. No clear pulses were recognized in a note. The fundamental frequency was about $1.7 \mathrm{kHz}$ and the second harmonic band (about $3.4 \mathrm{kHz}$ ) was dominant.

Males were calling on the banks of rice paddies. In Mudigere, Bufo scaber were also actively calling in the same rice paddies (Kuramoto and Joshy, in press).

\section{Etymology}

The specific name is derived from the Latin granosus (meaning granular), referring to the more or less granulated dorsum of this species.

\section{Notes}

We collected this species in Talagini, Mudigere, Kudremukh, Kirundadu and Madikeri, all in the Western Ghats. This frog was commonly seen in the paddy fields and small ditches around human habitations.

\section{Fejervarya kudremukhensis sp. nov.}

(Figs. 7C, 8D and 9B, Table 1)

Large haplotype 2 (hpL2) in the above comparisons.

Fejervarya cf. nilagirica in Kurabayashi et al. (2005).

\section{Diagnosis}

A large Fejervarya species, mean SVL being $49 \mathrm{~mm}$ in females and $41 \mathrm{~mm}$ in males. Dermal ridges on the back are generally few and short compared with $F$. mudduraja. On average, the hindlimb length relative to SVL is larger than in $F$. brevipalmata; the head width, eyelid width, eye diameter and tympanum diameter, all relative to SVL, are smaller than in F. keralensis; foot length relative to femur length is larger than in F. keralensis; tibia length relative to SVL is larger than in $F$. nilagirica; hand length, finger length and toe length, all relative to SVL, are smaller than in $F$. mudduraja; and head length relative to head width is larger than in $F$. keralensis (Table 3). Advertisement calls consist of 59 notes with a long initial note.

\section{Holotype}

BNHS 4653, male collected from Kudremukh on 10 June 2003. SVL: $40.8 \mathrm{~mm}$.

\section{Paratypes}

BNHS 4654, male collected from Kudremukh on 10 June 2003. SVL: $43.3 \mathrm{~mm}$. BNHS 4655, female collected from Talapu, Madikeri, on 17 July 2004. SVL: $42.3 \mathrm{~mm}$. BNHS 4656, male collected from Mudigere on 9 July 2005. SVL: $43.4 \mathrm{~mm}$.

\section{Description of holotype (measurements in $\mathrm{mm}$ )}

Vomerine teeth long ovoid, forming blunt oblique series between choanae; head wider than long (HL: 12.2; HW: 12.8); snout moderately pointed; loreal region concave; canthus rostralis blunt; nostril nearly equidistant from tip of snout and from eye (S-N: 3.6; N-E: 3.8); inter-narial distance greater than inter-orbital distance (N-N: 3.8; E-E: 2.8), the latter smaller than upper eyelid width (ELW: 3.0); tympanum about half $(52 \%)$ of eye in diameter (ED: 4.1; TD: 2.3).

Fingers free with rounded tip; finger lengths $4<2<1<3$ (F1: 4.9; F2: 4.1; F3: 5.0; F4: 3.7); subarticular and palmar tubercles well developed.

Hindlimb relatively long (HLL/SVL: 1.80); tibia longer than femur (FEL: 21.9; TIL: 23.6); toe lengths $1<2<5<3<4$ (T1: 4.0; T2: 8.6; T3: 13.1; T4: 19.4; T5: 11.6); toe tip rounded; webs I2-2II $2-3$ III $2 \frac{1}{2}-3 \frac{1}{2}$ IV $3 \frac{1}{2}-2 \mathrm{~V}$, relatively narrow, extending to middle portions of metatarsals; inner metatarsal tubercle relatively large (IMT: 3.4), compressed; outer metatarsal tubercle small (OMT: 1.4).

Dorsal dermal ridges and tubercles relatively few; interrupted reverse V-shaped ridge on dorsum at level of forelimbs; dorsum also with a few 
short longitudinal ridges and large and small elliptical ridges; supra-tympanic fold distinct; limbs without granules; ventral side smooth.

In preservative, dorsum dark brown, with black markings on large ridges; pale middorsal stripe from snout to vent, widening behind inverse V-shaped ridge, forming round pale marking; conspicuous white line from behind eye to shoulder; black bands connecting upper and lower jaws; lateral side with black reticulate markings; cross bars on anterodorsal surface of thigh, mottling on posterior side; cross bars on outer surface of tibia, tarsus and foot; thin white tibio-tarsal stripe from inner central portion of tibia through ankle to outer central portion of tarsus; ventral side white with black patch on throat.

\section{Variation}

Of the 22 specimens examined, five had a broad mid-dorsal stripe, 16 had a narrow middorsal stripe, and the remaining one lacked the stripe. This specimen and two of the specimens having the mid-dorsal stripe lacked the tibio-tarsal stripe. The large round dorsal marking was present in 10 specimens.

The throat was immaculate in females, but with one exceptional individual that had six faint longitudinal series of small dots on the throat and breast.

\section{Call structure}

The structure of advertisement calls of this species was reported by Kuramoto and Joshy (2001, as Limnonectes cf. keralensis). Each of the calls recorded at Kudremukh on 3 July 1999 at 22 C (Fig. 9B) consisted of 5-9 notes, with mean duration of $0.91 \mathrm{~s}(n=21)$. The first note was long and showed frequency modulation. The dominant frequency was about $3.6 \mathrm{kHz}$.

\section{Etymology}

The specific name refers to Kudremukh, the type locality of this species.

\section{Notes}

Daniels (2005) regarded the narrow tibio- tarsal stripe to be a characteristic feature of $F$. brevipalmata. However, only three of the nine BNHS specimens of $F$. brevipalmata actually had a tibio-tarsal stripe. We collected this frog from Talagini, Mudigere, Kudremukh, Madikeri and Kirundadu, all in the Western Ghats. The frogs were found on the ground, in wetlands and on the banks of ditches, but never in paddy fields. This species was partially sympatric with $F$. mudduraja as mentioned above.

\section{Fejervarya sahyadris \\ (Dubois, Ohler and Biju, 2001) \\ (Figs. 8E and 10A; Table 1)}

Minervarya sahyadris Dubois, Ohler and Biju, 2001. Alytes 19: 58. Type locality: Gundia, Kempholey forest, Hassan, Karnataka.

This frog is readily distinguishable from the other congeneric species by its distinctly smaller body size, white line along the margin of the upper jaw, and short leg length relative to SVL. A detailed description was given by Dubois et al. (2001).

\section{Variation}

In males, the anterior part of the thigh was black. The black area extended on the lateral side of the body to the forelimb base. The vocal sac extended to the level of forelimbs, and its posterior portion was grayish. A dark dorso-lateral line existed in all but one of the 12 specimens examined, but was confined to the posterior part of the body in six specimens. Two specimens had a narrow mid-dorsal stripe.

\section{Call structure}

The structure of calls of $F$. sahyadris was reported by Kuramoto and Joshy (2001) and Kadadevaru et al. (2002) (both as Limnonectes syhadrensis). We recorded calls at Karnoor on 10 July 2004 at 27 C (Fig. 10A), at Aralam on 14 July 2005 at 25 C, and at Bajipe on 22 July 2005 at $25.5 \mathrm{C}$. In the calls recorded in Bajipe, the number of notes was $12.4 \pm 2.8$, the call duration was $0.87 \pm 0.23 \mathrm{~s}$, the noterepetition rate was $15.7 \pm 2.0$ notes/s $(n=10)$, 

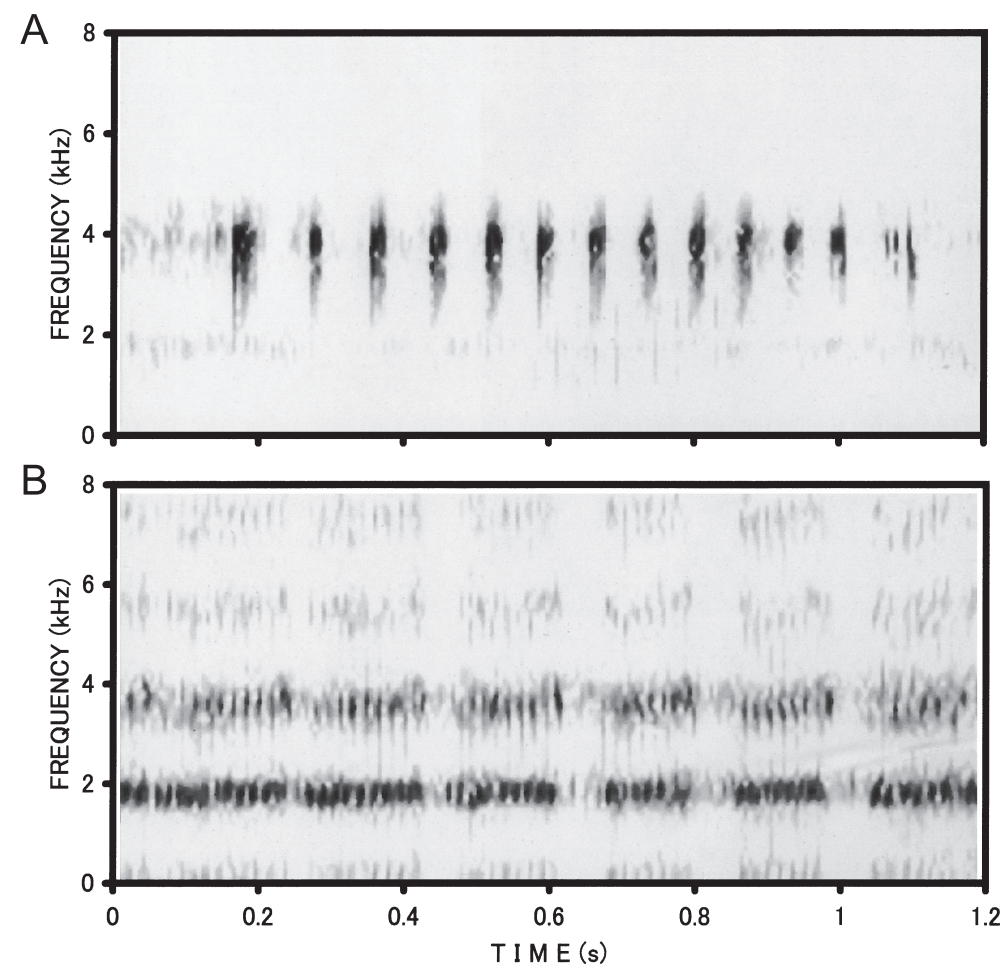

FIG. 10. Sound spectrograms of the advertisement calls of $F$. sahyadris (A) and $F$. caperata (B) (FlatTop window, $323 \mathrm{~Hz}$ bandwidth).

and the dominant frequency was about $3.7 \mathrm{kHz}$. We could not recognize the harmonic bands reported by Kadadevaru et al. (2002).

\section{Notes}

Originally, this taxon was placed in the new genus Minervarya (Dubois et al., 2001). However, our mtDNA sequence analysis revealed that the taxon is nested in Fejervarya (our unpublished data: see Fig. 2).

This frog has been confused with $F$. syhadrensis. The original description of $F$. syhadrensis defined the species as a "dwarf" race similar to Rana (=Fejervarya) limnocharis nilagirica with a short hindlimb and under-developed web (Annandale, 1919). Daniels (1998) added another character state, "upper lip white", as diagnostic of $F$. syhadrensis and regarded this species to be the smallest among frogs occurring in the Western Ghats. Based on these descriptions we erroneously identified $F$. sahyadris as $F$. syhadrensis in our previous works (Kuramoto and Joshy, 2000, 2001). Thus, the call structure and breeding behavior of "Limnonectes syhadrensis" reported by Kadadevaru et al. (2002) are actually of $F$. sahyadris.

We collected this species in Mangalore (Bajipe, Kadri, Padil), Bhatkal, Talagini, Karnoor, and Aralam. Males were calling on the ground near small water pools or in wetlands. This frog was rarely found in paddy fields. In BNHS, there were many specimens collected from Goa.

Fejervarya caperata sp. nov.

(Figs. 7D, 8F and 10B; Table 1)

Small haplotype $2(\mathrm{hpS} 2)$ in the above comparisons.

Fejervarya sp. (hpB) in Kurabayashi et al. (2005). 


\section{Diagnosis}

A small Fejervarya species, mean SVL being $33 \mathrm{~mm}$ in females and $29 \mathrm{~mm}$ in males. Body is relatively slender, with dermal ridges on dorsum. These ridges are mostly long compared with those of $F$. granosa, and tend to form four longitudinal lines. On average, the hand length relative to SVL is larger than in $F$. syhadrensis, and the head length and head width, both relative to SVL, are smaller than in $F$. granosa. The eyelid width relative to inter-orbital space is larger than in F. syhadrensis (Table 3). Advertisement call is a long trill composed of many notes with clear pulses.

\section{Holotype}

BNHS 4657, female collected from Karnoor on 11 July 2004. SVL: $35.9 \mathrm{~mm}$.

\section{Paratypes}

BNHS 4658, male collected in Bajipe, Mangalore, on 6 July 2004. SVL: $29.3 \mathrm{~mm}$. BNHS 4659, female collected in Talagini on 23 July 2004. SVL: 34.9 mm. BNHS 4660, female collected in Talapu, Madikeri, on 9 July 2006. SVL: $32.7 \mathrm{~mm}$.

\section{Description of holotype (measurements in $\mathrm{mm}$ )}

Vomerine teeth long, ellipsoidal, forming blunt oblique series between choanae; anterior part of vomerine teeth series nearly touching choanae; tip of tongue bifurcated.

Head slightly wider than long (HL: 10.3; HW: 10.5); snout slightly pointed from above; loreal region heavily concave; canthus rostralis rounded; nostril nearer to tip of snout than to eye (S-N: 3.1; N-E: 3.5); inter-narial distance greater than inter-orbital distance (N-N: 3.1 ; E-E: 2.7), the latter smaller than upper eyelid width (ELW: 3.0); tympanum about $60 \%$ of eye in diameter (ED: 3.7; TD: 2.3).

Fingers free; finger tip rounded; finger lengths $4<2<1<3$ (F1: 3.7; F2: 3.4; F3: 5.8; F4: 3.0); subarticular and palmar tubercles distinct.

Hindlimb relatively short (HLL/SVL: 1.54); tibia longer than femur (FEL: 17.2; TIL: 18.1); toe tip rounded; toe lengths $1<2<3<5<4$
(T1: 2.4; T2: 6.0; T3: 8.4; T4: 11.2; T5: 9.4); webs I2-2II2-2III2-3IV3-2V; outermost web extending to bases of metatarsals; dermal fold along outer edge of fifth toe; subarticular tubercle moderate; inner metatarsal tubercle moderate (IMT: 1.3).

Snout and upper eyelid smooth; dorsum with many longitudinal ridges roughly forming four longitudinal series, inner pair of the series close to lateral sides of mid-dorsal stripe; the outer series of ridges running from eye to groin; indistinct small longitudinal ridges between inner and outer series; lateral side of body with short, slightly thick, roundish ridges; supra-tympanic fold ending at postero-ventral portion of tympanum, not reaching forelimb base; dorsal surface of thigh smooth; tibia with small granules dorsally, smooth ventrally.

In preservative, brown on dorsum, with longitudinal ridges and their outer sides darker; mid-dorsal stripe broad, pale; black bands connecting upper and lower jaws indistinct on lower jaw; pale line from eye through lower half of tympanum to base of forelimb; lateral side of body irregularly marbled; cross bars on forelimb; three thick cross bars on anterodorsal surface of thigh, posterior surface with bold markings; cross bars on tibia, tarsus, and foot.

\section{Variation}

Of the 38 specimens examined, 17 had a broad mid-dorsal stripe, 14 had a narrow middorsal stripe, and seven had no such stripe at all. In a few specimens including two paratypes (BNHS 4658 and BNHS 4659), two dermal ridges at the center of dorsum formed interrupted inverse $\mathrm{V}$-shaped ridges.

\section{Call structure}

Advertisement calls were recorded at Karnoor on 5 August 2001 at an air temperature of $27.5 \mathrm{C}$. The call consisted of many pulse groups (notes). The note was $0.122 \pm 0.008 \mathrm{~s}$ in duration and was repeated at an interval of $0.185 \pm 0.009 \mathrm{~s}(\mathrm{n}=17)$. The number of pulses in a note was $7.35 \pm 0.49$ and the pulse repetition rate was $56.89 \pm 2.61$ pulses $/ \mathrm{s}$. The domi- 
nant (and fundamental) frequency band was at $1.8-1.9 \mathrm{kHz}$, and a second harmonic band occurred at $3.6-3.9 \mathrm{kHz}$ (Fig. 10B). The frequency bands of the first pulse tended to be somewhat lower, and those of the last pulse were higher than those of the other pulses. The advertisement calls recorded at Padil, Mangalore and reported by Kuramoto and Joshy (2001) as of Limnonectes limnocharis was essentially identical in structure.

The call of $F$. caperata is similar to that of $F$. syhadrensis in structure, because the latter also consists of many successive pulse groups (Dubois, 1975, 1976). However, the calls of $F$. syhadrensis have much higher dominant frequencies $(2.7-4.1 \mathrm{kHz})$, more numerous pulses in a note (11-14 in fast call, 18-23 in slow call), and shorter note lengths $(0.06-0.07 \mathrm{~s}$ in fast call, $0.09-0.12 \mathrm{~s}$ in slow call) than those of F. caperata.

\section{Etymology}

The specific name is derived from the Latin caperatus meaning "wrinkled", referring to the characteristic long dermal ridges on the dorsal surface of body of this frog.

\section{Notes}

This species was commonly found in paddy fields and small ditches around houses. We collected this frog in Mangalore (Bajipe, Padil), Talagini, Kudremukh, Mudigere, Karnoor and Madikeri. In Talagini and Mudigere, $F$. caperata males were calling among large choruses of $F$. granosa. Tadpoles of $F$. caper$a t a$, as identified by mtDNA sequencing, were collected in paddy fields on 6 July 2004 in Bajipe and on 10 July 2004 in Karnoor.

\section{DISCUSSION}

Both the two large-bodied species, F. mudduraja and $F$. kudremukhensis, and the two small-bodied species, $F$. granos $a$ and $F$. caper$a t a$, can be regarded as cryptic species that are difficult to identify by morphological traits alone. From Fig. 7, it may seem that discrimination of these species from each other is rather easy. However, their seemingly clear differences are actually obscure due to the extensive intraspecific variations in relevant characters in each species. Although there are statistically significant interspecific morphological differences, these differences are not conclusive for identification, because there is an overlap in every measurement or ratio between the species. Even between large- and the small-bodied species, juvenile frogs cannot be discriminated easily.

For many other groups of cryptic or sibling species of anurans, advertisement call structure often offers a useful tool for specific identification (e.g. Blair, 1958; Mecham et al., 1973; Kuramoto, 1980). As long as available data are concerned, advertisement calls of the present subject also seem to be species specific in structure, being applicable to species identification. Although the advertisement call of F. mudduraja was not available, it is predicted that $F$. mudduraja has a call structure distinct from that of $F$. kudremukhensis, because the two species occur sympatrically. Apparently, acoustic traits have diverged more extensively than morphological traits in this group of frogs, as in several other frog groups previously described (e. g. Kuramoto, 1975, 1980, 1986).

Most Fejervarya species found in the central Western Ghats live sympatrically or parapatrically. In montane rice paddies, $F$. granosa and $F$. caperata, and occasionally $F$. sahyadris, were observed calling together, although $F$. granosa was predominant in number. Apparently, $F$. mudduraja, F. rufescens, and F. kudremukhensis did not breed in rice paddies, but we could not confirm their breeding sites. These species were collected in wetlands (mostly flooded grassland during the rainy season), bushes in the vicinity of small streams or ditches, or on the mountain paths. Most specimens of $F$. sahyadris were collected in wetlands and temporary pools in the vicinity of either rice paddies or human residences.

Thus, there seems to be a fairly clear segregation of habitat into rice-paddy breeders and wetland breeders. Fejervarya rufescens, $F$. 
caperata and $F$. sahyadris were observed in lowlands (Bhatkal, Udupi, and Mangalore), as well as mountainous regions, whereas the other three species were collected only in mountainous regions.

The Western Ghats is designated as one of the biodiversity hot spots of the World (Biju, 2001). The presence of so many species in several particular frog genera, such as Fejervarya, Indirana, Nyctibatrachus, Micrixalus and Philautus, may reflect an active speciation in this region. We expect that in many genera many species and subspecies have been actively produced locally and future studies will reveal more extensive biodiversity than is currently recognized (as assumed by Biju [2001]). An incredible number of new Philautus species (35 in number) were described recently in Sri Lanka, an area that exhibits a close herpetofaunal relationship with that of southern India and the Western Ghats (Manamendra-Arachchi and Pethiyagoda, 2005: Meegaskumbara and Manamendra-Arachchi, 2005). Biju (2001) suggested the existence of about 100 cryptic frog species that need future examination and description from the Western Ghats. We have found another distinct mtDNA haplotype of the genus Fejervarya in Aralam, which is not named here because we have collected only one specimen. Distinct mtDNA haplotypes were also detected in the genus Euphlyctis (Kurabayashi et al., 2005). Also, our preliminary results showed that in each of $F$. rufescens and $F$. sahyadris, samples from Karnataka and Kerala have considerably diverged from each other, possibly representing an intermediate stage in the speciation process.

Finally, we would like to emphasize the importance of retaining DNA sequence data or tissue samples that enable subsequent DNA sequencing of type specimens. This is particularly true when the types represent species belonging to cryptic species complexes, for which species identification or phylogenetic inference is so difficult solely on the morphological ground.

\section{ACKNOWLEDGMENTS}

We thank A. Dubois (MNHN) and N. Chaturvedi and V. Giri (BNHS) for allowing us to examine museum specimens in their care. Assistance in the field by S. Rao, T. B. R. Hegde, P. K. Bhat, and K. G. Yogish is much appreciated. Special thanks are due to the Principal and management staff of St. Aloysius College for the support and facilities.

\section{LITERATURE CITED}

ANDERS, C. 2002. Class Amphibia (Amphibians). p. 133-348. In: H. H. Schleich and W. Kästle (eds.), Amphibians and Reptiles of Nepal. A. R. G. Gantner Verlag, Ruggell.

ANNANDALE, N. 1919. The fauna of certain small streams in the Bombay presidency. Rec. Indian Mus. 19: 109-161, 7 pls.

BIJU, S. D. 2001. A synopsis of the frog fauna of the Western Ghats, India. Occ. Publ. Indian Society of Chemists and Biologists 1: 1-24.

BLAIR, W. F. 1958. Mating call in the speciation of anuran amphibians. Am. Nat. 92: 27-51.

BoulEnger, G. A. 1890. The Fauna of British India Including Ceylon and Burma. Reptilia and Amphibia. Taylor and Francis, London.

BOULENGER, G. A. 1904. Description of a frog from Ceylon, hitherto confounded with "Rana limnocharis". Spolia Zeylan. 2: 73-74.

Boulenger, G. A. 1920. A monograph of the south Asian, Papuan, Melanesian and Australian frogs of the genus Rana. Rec. Indian Mus. 20: 1226.

ChANDA, S. K. 2002. Hand Book-Indian Amphibians. Zoological Survey of India, Kolkata.

DANIEL, J. C. 2002. The Book of Indian Reptiles and Amphibians. Oxford Univ. Press, Oxford.

DANIELS, R. J. R. 1992. Range extension in some south Indian amphibians. Hamadryad 17: 4042.

DANIELS, R. J. R. 1998. A Field Guide to the Frogs and Toads of the Western Ghats: India. Private Circulation (Reproduced from Cobra 27: 1-25; 28: 1-24; 29: 1-13).

DANIELS, R. J. R. 2005. Amphibians of Peninsular 
India. Universities Press (India) Private Ltd., Hyderabad.

DJONG, H. T., M. M. ISLAM, M. NishiokA, M. Matsui, H. Ota, M. Kuramoto, M. M. R. Khan, M. S. Alam, A. De Silva, W. Khonsue, AND M. SUMIDA. 2007. Genetic relationships and reproductive isolation mechanisms among the Fejervarya limnocharis complex from Indonesia (Java) and other countries. Zool. Sci. 24: 360-375.

DuBoIs, A. 1975. Un nouveau complexe d'espèces jumelles distinguées par le chant: les grenouilles du Nèpal voisines de Rana limnocharis Boie (Amphibiens, Anoures). C. R. Acad. Sc. Paris, Ser. D. 281: 1717-1720.

Dubors, A. 1976. Chants et ecologie chez les amphibiens du Nepal. Colloq. Internat. C. N. R. S. 268: 109-118.

DuBoIS, A. 1984. Note preliminare sur le groupe de Rana limnocharis Gravenhorst, 1829 (Amphibiens, Anoures). Alytes 3: 143-159.

Dubois, A. AND A. OHLer. 2000. Systematics of Fejervarya limnocharis (Gravenhorst, 1829) (Amphibia, Anura, Ranidae) and related species. 1. Nomenclatural status and type-specimens of the nominal species Rana limnocharis (Gravenhorst, 1829). Alytes 18: 15-50.

Dubois, A., A. Ohler, AND S. D. BiJu. 2001. A new genus and species of Ranidae (Amphibia, Anura) from south-western India. Alytes 19: 5379.

DutTA, S. K. AND K. MANAMENDRA-ARACHCHI. 1996. The Amphibian Fauna of Sri Lanka. Wildlife Heritage Trust of Sri Lanka. Colombo.

DutTA, S. K. AND N. SINGH. 1996. Status of Limnonectes limnocharis (Anura: Ranidae) species complex in Asia. Zoos' Print 11(8): 15, 21.

FEI, L., C.-Y. YE, J.-P. JANG, AND F. XIE. 2002. On taxonomic status of Rana limnocharis group with revision of nomenclature of the rice frog from China. Herpetol. Sinica 9: 88-96. (In Chinese with English abstract)

Frost, D. R. 2007. Amphibian Species of the World: an Online Reference. V. 5.0 (1 February 2007). The American Museum of Natural History. New York. [Electronic database available at http://research.amnh.org/herpetology/ amphibia/index.php]

GÜNTHER, A. 1875. Third report on collections of Indian reptiles obtained by the British Museum. Proc. Zool. Soc. London 1875: 567-577.

JERDON, T. C. 1853. Catalogue of reptiles inhabiting the Peninsula of India. J. Asiat. Soc. Bengal 22: 462-479, 522-534.

KADADEvaru, G. G., R. D. KANAMADI, AND H. SCHNEIDER. 2000. Advertisement call of two Indian ranids, Indirana beddomii and Tomopterna rufescens. Amphibia-Reptilia 21: 242-246.

KADADEVARU, G. G., R. D. KANAMADI, AND H. SCHNEIDER. 2002. Advertisement call, courtship and mating behaviour of the frog, Limnonectes syhadrensis from Western Ghats. Cur. Sci. 82: 503-505.

Kurabayashi, A., M. KuRAMOTO, H. Joshy, AND M. SUMIDA. 2005. Molecular phylogeny of the ranid frogs from southwest India based on the mitochondrial ribosomal RNA gene sequences. Zool. Sci. 22: 525-534.

KURAMOTO, M. 1975. Mating calls of Japanese tree frogs (Rhacophoridae). Bull. Fukuoka Univ. Educ., Pt. III 24: 67-77.

KURAMOTO, M. 1980. Mating calls of treefrogs (genus Hyla) in the Far East, with a description of a new species from Korea. Copeia 1980: 100108.

KuRAmoto, M. 1986. Call structures of the rhacophorid frogs from Taiwan. Sci. Rep. Lab. Amphibian Biol., Hiroshima Univ. 8: 45-68.

KuRAMOTO, M. AND S. H. JoShy. 2000. Sperm morphology of some Indian frogs as revealed by SEM. Cur. Herpetol. 19: 63-70.

KURAMOTO, M. AND S. H. JOSHY. 2001. Advertisement call structures of frogs from southwestern India, with some ecological and taxonomic notes. Cur. Herpetol. 20: 85-95.

KURAMOTO, M. AND S. H. Joshy. In press. Advertisement calls of Indian and Sri Lankan frogs. J. Bombay Nat. Hist. Soc..

MANAMENDRA-ARACHCHI, K. AND R. PETHIYAGODA. 2005. The Sri Lankan shrub-frogs of the genus Philautus Gistel, 1848 (Ranidae: Rhacophorinae), with description of 27 new species. Ruffl. Bull. Zool., Suppl. 12: 163-303.

MeCham, J. S., M. J. Littlejohn, R. S. Oldham, L. E. BRown, AND J. R. BRown. 1973. A new 
species of leopard frog (Rana pipiens complex) from the plains of the central United States. Occ. Pap. Mus. Texas Tech. Univ. 18: 1-11.

MEEGASKUMBURA, M. AND K. MANAMENDRAARACHCHI. 2005. Description of eight new species of shrub frogs (Ranidae: Rhacophorinae: Philautus) from Sri Lanka. Ruffl. Bull. Zool., Suppl. 12: 305-338.

Myers, C. W. AND W. E. Duellman. 1982. A new species of Hyla from Cerro Colorado, and other tree frog records and geographical note from western Panama. Am. Mus. Novit. 2752: 1-32.

PILlAI, R. S. 1979. A new species of Rana (family Ranidae) from Western Ghats, S. India. Bull. Zool. Surv. India 2: 39-42.

RAO, C. R. N. 1922. Notes on Batrachia. J. Bombay Nat. Hist. Soc. 28: 439-447.

RAO, C. R. N. 1937. On some new forms of Batrachia from S. India. Proc. Indian Acad. Sci. (B)6: 387-427.

TODA, M., M. MATSUI, M. NISHIDA, AND H. OTA. 1998. Genetic divergence among southeast and east Asian populations of Rana limnocharis (Amphibia: Anura), with special reference to sympatric cryptic species in Java. Zool. Sci. 15: 607-613.

Veith, M., J. Kosuch, A. OHLer, AND A. Dubois. 2001. Systematics of Fejervarya limnocharis (Gravenhorst, 1829) (Amphibia, Anura, Ranidae) and related species. 2. Morphological and molecular variation in frogs from the Greater Sunda Islands (Sumatra, Java, Borneo) with the definition of two species. Alytes 19: 5-28.

\section{APPENDIX 1}

\section{Specimens examined}

Fejervarya brevipalmata: BNHS 2940, 2947, 2955, 2957, 2958, 2989, 3025, 3040, 4075.

Fejervarya caperata: RBRL OS012, 990702, 00061551, 01080301, 01080517-01080523, 03052302, 03052304, 03052401, 03052402, 03052602, 03052604, 04070604 (Paratype: BNHS 4658), 04070605, 04070606, 04071123, 04071124 (Holotype: BNHS 4657), 0407112504071133, 04072305 (Paratype: BNHS 4659), 04072307-04072309, 04072311-04072315, 05071408, 05072203-05072210, 06060915,
06070933 (Paratype: BNHS 4660), 06071501, 06071503, 06071505-06071507, 0607240706072410.

Fejervarya granosa: RBRL 00061507, 00062608-00062613, 01081108, 01081109, 01081608, 01081609, 03060703-03060706, 04071620 (Holotype: BNHS 4649), 0407162304071627，04071629，04071630，04072306 (Paratype: BNHS 4650), 04072310, 05070901, 05070902 (Paratype: BNHS 4651), 0507090305070916, 06070910, 06070912, 06070913 (Paratype: BNHS 4652), 06070914, 0607091606070923, 06070930-06070932.

Fejervarya keralensis: BNHS 1896, 2022, 2083, 2365-1, 2545A, 2865, 3063, 3078-3080.

Fejervarya kudremukhensis: RBRL 00061503, 00061504, 00061515, 00061550, 00062614, 01081102, 01081103, 01081116, 0108160501081607, 03061007, 03061008 (Paratype: BNHS 4654), 03061009-03061011 (Holotype: BNHS 4653), 04071617 (Paratype: BNHS 4655), 05070917, 05070918 (Paratype: BNHS 4656), 05070919, 05070920, 0507093005070934.

Fejervarya mudduraja: RBRL OS001, OS002, OS021, 03060701 (Paratype: BNHS 4646), 04071615 (Holotype: BNHS 4645), 04071616 (Paratype: BNHS 4647), 04071621, 04071622, 04071625, 04071628, 04071631-04071636, 05070917 (Paratype: BNHS 4648), 05070930, 06070909.

Fejervarya nilagirica: MNHN 1984.23341984.2344. (incl. Neotype 1984.2340)

Fejervarya rufescens: RBRL 0006261900062621, 00062651, 01080502, 01081106, 01081122, 03052603, 04071137, 04071601, 05071405-05071407. MNHN 1984.2345-1984. 2357. (incl. Neotype 1984.2348)

Fejervarya sahyadris: RBRL 0006070900060713, 00062622-00062625, 01080701, 04071101-04071112, 04072316-03072318, 05071401-05071404, 05072212. BNHS 2592, 2593, 2638, 2753, 2757, 2796, 2797, 2800, 2891.

Fejervarya syhadrensis: MNHN 1975.1722, 1975.2035-1975.2062, 1996.9259-1996.9265. 


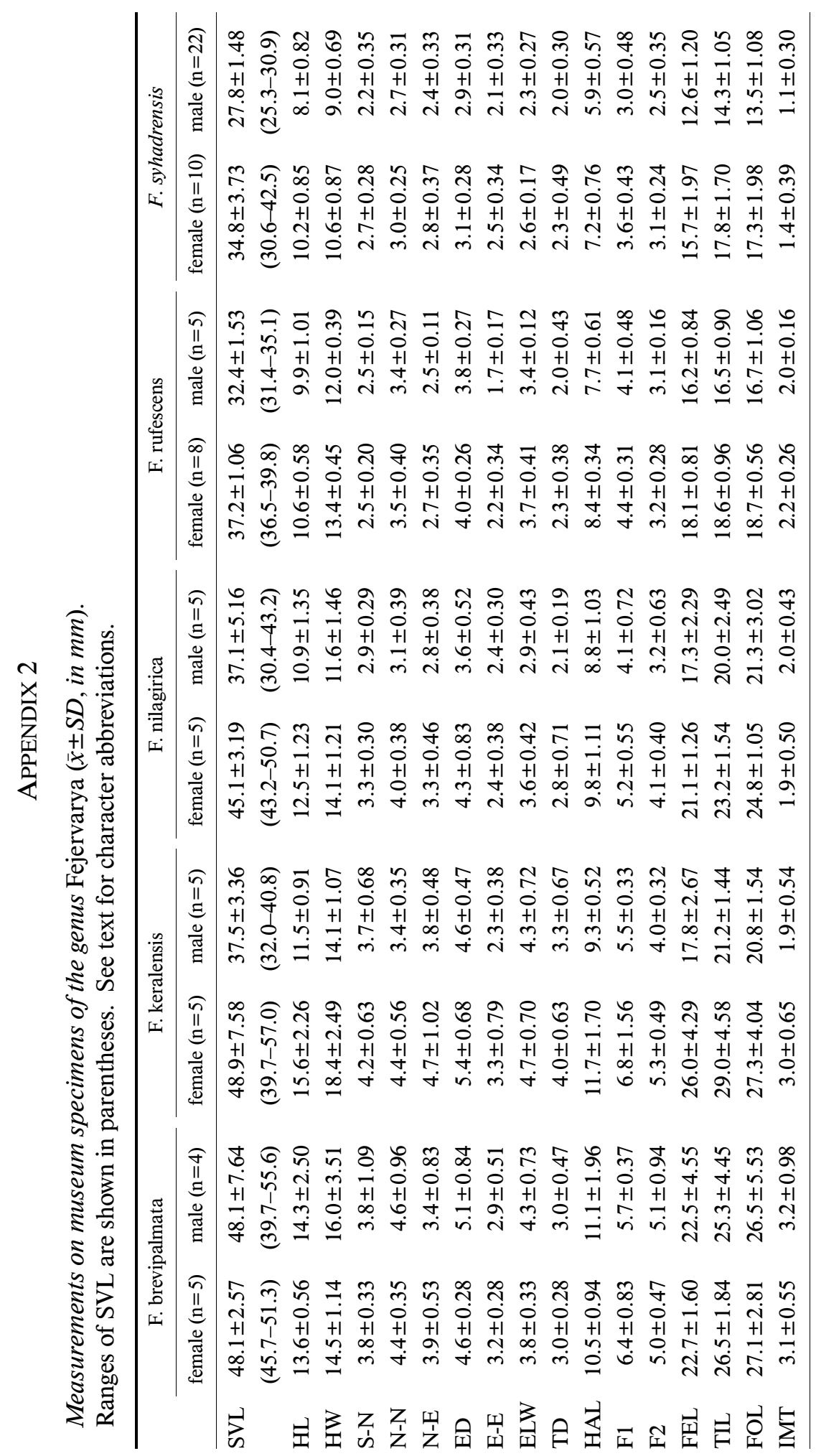




\section{APPENDIX 3}

Accession numbers of mtDNA sequencing for the type specimens of new Fejervarya species.

\begin{tabular}{lccc}
\hline \multirow{2}{*}{ Species } & BNHS no. & \multicolumn{2}{c}{ Accession no. } \\
\cline { 3 - 4 } F. mudduraja & & $12 \mathrm{~S}$ & $16 \mathrm{~S}$ \\
& 4645 (Holotype) & $\mathrm{AB} 355820$ & $\mathrm{AB} 355833$ \\
& 4646 (Paratype) & $\mathrm{AB} 167918^{*}$ & $\mathrm{AB} 169746^{*}$ \\
& 4647 (Paratype) & $\mathrm{AB} 355821$ & $\mathrm{AB} 355834$ \\
F. granosa & 4648 (Paratype) & $\mathrm{AB} 355822$ & $\mathrm{AB} 355835$ \\
& 4649 (Holotype) & $\mathrm{AB} 355823$ & $\mathrm{AB} 355836$ \\
& 4650 (Paratype) & $\mathrm{AB} 355824$ & $\mathrm{AB} 355837$ \\
F. kudremukhensis & 4653 (Holotype) & $\mathrm{AB} 167921 *$ & $\mathrm{AB} 167949 *$ \\
& 4651 (Paratype) & $\mathrm{AB} 355825$ & $\mathrm{AB} 355838$ \\
& 4652 (Paratype) & $\mathrm{AB} 167922^{*}$ & $\mathrm{AB} 167950 *$ \\
& 4655 (Paratype) & $\mathrm{AB} 355827$ & $\mathrm{AB} 355840$ \\
F. caperata & 4656 (Paratype) & $\mathrm{AB} 355828$ & $\mathrm{AB} 355841$ \\
& 4657 (Holotype) & $\mathrm{AB} 355829$ & $\mathrm{AB} 355842$ \\
& 4658 (Paratype) & $\mathrm{AB} 355830$ & $\mathrm{AB} 355743$ \\
& 4659 (Paratype) & $\mathrm{AB} 355831$ & $\mathrm{AB} 355844$ \\
& 4660 (Paratype) & $\mathrm{AB} 355832$ & $\mathrm{AB} 355845$ \\
\hline
\end{tabular}

* Data from Kurabayashi et al. (2005), in which F. mudduraja and $F$. kudremukhensis were desiganated as $F$. cf. brevipalmata and $F$. cf. keralensis, respectively.

Accepted: 7 December 2007 